\title{
Analysis of Endogenous D-Amino Acid-Containing Peptides in
}

\section{Metazoa}

\author{
Lu Bai $^{1,3}$, Sarah Sheeley ${ }^{2}$, and Jonathan V. Sweedler $2,3,{ }^{*}$ \\ ${ }^{1}$ Department of Molecular and Integrative Physiology, University of Illinois at Urbana-Champaign, \\ Urbana, Illinois 61801 \\ ${ }^{2}$ Department of Chemistry, University of Illinois at Urbana-Champaign, Urbana, Illinois 61801 \\ ${ }^{3}$ Beckman Institute for Advanced Science and Technology, University of Illinois at Urbana- \\ Champaign, Urbana, Illinois 61801
}

\begin{abstract}
Peptides are chiral molecules with their structure determined by the composition and configuration of their amino acid building blocks. The naturally occurring amino acids, except glycine, possess two chiral forms. This allows the formation of multiple peptide diastereomers that have the same sequence. Although living organisms use L-amino acids to make proteins, a group of D-amino acidcontaining peptides (DAACPs) has been discovered in animals that have at least one of their residues isomerized to the D-form via an enzyme-catalyzed process. In many cases, the biological functions of these peptides are enhanced due to this structural conversion. These DAACPs are different from those known to occur in bacterial cell wall and antibiotic peptides, the latter of which are synthesized in a ribosome-independent manner. DAACPs have now also been identified in a number of distinct groups throughout the Metazoa. Their serendipitous discovery has often resulted from discrepancies observed in bioassays or in chromatographic behavior between natural peptide fractions and peptides synthesized according to a presumed all-L sequence. Because this L-to-D post-translational modification is subtle and not detectable by most sequence determination approaches, it is reasonable to suspect that many studies have overlooked this change; accordingly, DAACPs may be more prevalent than currently thought. Although diastereomer separation techniques developed with synthetic peptides in recent years have greatly aided in the discovery of natural DAACPs, there is a need for new, more robust methods for naturally complex samples. In this review, a brief history of DAACPs in animals is presented, followed by discussion of a variety of analytical methods that have been used for diastereomeric separation and detection of peptides.
\end{abstract}

\section{INTRODUCTION}

It has long been assumed that in higher animals, natural amino acids exist exclusively in the L-form. In the L-form, the - $\mathrm{COOH}$, $-\mathrm{NH} 2$ and - $\mathrm{R}$ groups are arranged clockwise around the chiral carbon atom, as shown in Fig. 1, with the hydrogen atom located away from the center; for the D-form, these groups are arranged counterclockwise around the chiral carbon atom. In recent years several D-amino acids have been found in the nervous system. These D-amino acids have been correlated with a number of diseases [1-3] and may be novel players in neurotransmission and development. Peptides that contain D-amino acids are even less understood than free $\mathrm{D}$-amino acids in higher animals and such peptides have now been found in a surprising range of animals (Fig. 2). While antibiotic peptides in bacteria and the peptidyl

*To whom correspondence should be addressed. Jonathan V. Sweedler, Phone: 217-244-4759, Fax: 217-265-6290, jsweedle @ illinois.edu. 
glycan in their cell walls [4] indicated their existence in prokaryotes, the presence of L-amino acids in peptides in higher organisms was accepted as an "unbreakable" norm. Naturally existing D-amino acid-containing peptides (DAACPs) did not receive the awareness and attention they enjoy today until 1981 , when the D-alanine-containing peptide, dermorphin, was isolated [5]. Over the last three decades, more than 30 examples of DAACPs in animals have been reported. Interestingly, they distribute in a number of different species, ranging from frogs [5-10], snails [11-25], crustaceans [26,27], spiders [28], and even mammals [29,30], spanning five phyla (Table 1). Importantly, isomerization of the residue has been found to be crucial for proper biological function. As one example, the cardioactive peptide $\mathrm{NdWFa}^{\mathrm{i}}$ (named after its sequence), isolated from two subspecies of Aplysia, has been found to be significantly more effective in enhancing the beating amplitude of an Aplysia heart at $10^{-10} \mathrm{M}$. However, the synthetic peptide NWFa has little effect, even at $10^{-6} \mathrm{M}$, indicating that the modification is essential for proper physiological function [13]. Why is this the case? It may be because naturally existing DAACPs, rather than their synthetic all-L-form counterparts, interact with the endogenous receptors to cause the required physiological responses [31]. It is also thought that the modified structure of DAACPs makes it more difficult for the peptides to be digested by endogenous peptidases, thus increasing the time DAACPs remain active [26]. There are many reports and reviews highlighting methods to characterize the chirality of the amino acids making up peptides in the analytical literature; this review emphasizes measurements related to naturally occurring DAACPs throughout Metazoa. DAACPs have been the subject of several reviews, with an excellent review emphasizing the biology of DAACPs by Kreil G. et al. [32] and another describing analytical approaches used to characterize natural DAACPs and other mammalian chiral peptides by Iida et al. [33].

Because DAACPs are naturally occurring peptides, a study to determine unknown peptides in a sample may now require a stereoselective analysis to characterize the peptide complement, for example, from a brain or toxic secretion. Of course, stereoselective measurements can be important for drug development and manufacture. For example, stereospecific analyses are important for ensuring quality control and can be required by regulatory authorities such as the U.S. Food and Drug Administration, and the European Medicines Agency because isomers usually possess different, and sometimes undesirable pharmacokinetic and toxicological profiles. Just as endogenous DAACPs are recognized stereoselectively by receptors, the chirality of peptide-based drugs can affect their efficacy and metabolism in many ways, so that specific stereoisomers can be more efficacious drugs than their isomers.

Although several methods are amenable to peptide analyses, due to the ever-improving performance capabilities of modern mass spectrometry (MS), most peptide measurement efforts use this approach extensively [34-37]. However, one of the challenges of detecting DAACPs lies in the zero mass shift of this modification, making them difficult to characterize using MS alone. Various analytical techniques are available that allow the physicochemical changes effected by conformational alteration to be measured, and a number are separationbased. The separation of peptide diastereomers depends on differences in the physicochemical properties of the all L-amino acid-containing peptides (LAACPs) and the DAACPs, and these changes are usually magnified with the use of chiral selectors embedded in stationary phases or added into mobile phases. The use of separations using chiral stationary phases (CSPs) and chiral mobile phase additives (CMPAs) in high performance liquid chromatography (HPLC) and capillary electrophoresis (CE) are highlighted below. Also discussed are MS and nuclear magnetic resonance (NMR) spectroscopy, as are hybrid approaches such as selective enzymatic digestion followed by MS characterization. 


\section{DAACP DISCOVERY: HISTORY AND BIOLOGICAL PERSPECTIVES}

While L-amino acids are utilized exclusively by ribosomes in translation, amino acids in the D-form have been found to exist in several antibiotic peptides such as gramicidin and tyrocidin [4]. It was later demonstrated that these peptides are assembled via thioester intermediates [38] through non-ribosomal pathways on multi-enzyme complexes in a stepwise fashion. Lantibiotics, a different class of peptide antibiotics derived from larger precursors produced by bacteria, also contain D-amino acids. These peptides, including nisin, subtilin, epidermin and cinnamycin, achieve their final forms via post-translational processing of the pre-peptides $[39,40]$.

Despite this knowledge, production of DAACPs has been considered primarily a prokaryotic function because eukaryotic cells use only L-amino acids in ribosome-mediated protein synthesis. However, since the discovery in 1981 of dermorphin, a bioactive DAACP isolated from skin secretions of the South American tree frog Phyllomedusa sauvagei [5], the notion that DAACPs are present in higher organisms began receiving greater attention. With Dalanine in the second position, dermorphin demonstrated high affinity and selectivity for $\mu$ type opiate receptors - on a molar basis, 1000 times more analgesic potency than morphinehowever, the all-L-form counterpart was devoid of bioactivity [6,8,31]. It was later shown that the D-alanine residue was encoded by the normal alanine codon GCG, suggesting that occurrence of the D-amino acid was via a post-translational modification (PTM) [41]. In the skin of the same frog species, as well as the sub-family Phyllomedusinae, researchers identified additional opiate peptides that contained D-amino acid residues. The deltorphins for example, are a class of DAACPs found to exhibit high selectivity and affinity for the $\delta$-type opiate receptor [6-9,31]. Interestingly, the amino terminal of the opioid peptides described above share the same sequence, Tyr-Xaa-Phe, where Xaa represents D-Ala, D-Met or D-Leu [32]. Other DAACPs discovered in frog skin secretions are the Bombinins, a peptide family isolated from Bombina variegata that exhibit antimicrobial activity, containing D-alloisoleucine instead of isoleucine [10,42].

DAACPs have also been identified in mollusks. Conotoxins in Conus venom represent a class of peptides that are heavily post-translationally modified, and more than 12 members belonging to the I- and M-superfamilies of conotoxin were found to contain a D-amino acid. Some of these DAACPs have L-to-D isomerization at the third or fourth residue from the amino end, and several such as conophan, conomarphin, r11a, r11b, and r11c have the D-residue at the third position from the C-terminus. Other molluscan neuropeptides were also found to be DAACPs. Achatin I (GdFAD) from the African giant land snail Achatina fulica was the first discovered peptide in this category [11]. While the D-amino acid-containing native peptide has potent neuroexcitatory effects, the all-L-form isomer achatin II (GFAD) lacks activity altogether. Fulicin (FdNEFVa) [43] and fulyal (YdAEFLa) [12], two peptides from the same species, were shown to be produced from the same prohormone precursor. As mentioned earlier, NdWFa from Aplysia has a more potent effect on heart rate than the all-L-form isomer, found in two sub-families $[13,44]$.

Among the diverse species in which DAACPs have also been discovered are crustacea (cHHA, cHHB, Prc CHH-II) [26,27], octopus (ocp-1/4) [24] and spiders (in venom) (IVB) [28]. The presence of DAACPs in platypus venom [29,30] demonstrated that these peptides can be found in mammals, and certainly raised questions about how prevalent DAACPs actually are and if many have been overlooked in peptide characterization studies.

Before describing methods to characterize them, it is worth briefly discussing the function of this unusual modification. The incorporation of a $\mathrm{D}$-amino acid into a peptide sequence appears to serve several functions: first, this modification allows more products from a single gene; 
second, a variety of physiological functions can be achieved through differential binding to the peptide's cognate receptor; and third, the altered structure can result in a distinct (usually greater) resistance to protease degradation and thus confers a different effective time frame.

Increasing evidence suggests that the L-to-D conversion is a PTM, not only because a normal codon has been found at the D-residue position [41] but more importantly, peptide isomerases from spider, frog and platypus have been isolated [45-47]. The spider isomerase is a cofactorindependent enzyme that has sequence similarities with serine protease. In spider venom, it selectively catalyzes the conversion of a serine residue at the third position from the $\mathrm{C}$-terminus, instead of the one in the middle region, indicating the specificity of this enzyme partly depends on steric factors [32,48]. Frog isomerase is thought to be a different type of enzyme, at least according to its sensitivity to chelators and inhibitors. These two enzymes seem to have differing preferences on the location of catalysis as D-amino acids have been found at different termini between frog and spider. Although the snail isomerase is not known, the relative location of $\mathrm{D}$-amino acids in a peptide sequence is at the second position from the $\mathrm{N}$-terminus, resembling most DAACPs from frog sources. Platypus isomerase is stable at temperatures as high as $55^{\circ} \mathrm{C}$, indicating a robust structure [47], but unfortunately, sequence information has yet to be determined due to difficulties in purification. Additionally, using ultrastructural immunohistochemistry, Gallois et al. [49] demonstrated that isomerization of the D-Phe residue in $\mathrm{CHH}$ occurs within the secretory granules. The fact that only a fraction of the $\mathrm{CHH}$ was in an isomerized form may indicate equilibrium between precursor and processed peptides.

\section{ANALYTICAL TECHNIQUES USED TO CHARACTERIZE DAACPS}

How does one differentiate an endogenous brain peptide - one that contains an amino acid in the D-form-from a complex mixture of partially characterized brain peptides present within an even more complex peptide mixture spanning many orders of magnitude in concentration? Even without analyzing for DAACPs, this is a complex measurement challenge. A new direction in peptide research has emerged in response to such analytical challenges, the field of peptidomics [34,35,50,51]. A peptidomics experiment that also seeks to determine DAACPs present in such samples represents a much more difficult task than quantifying the amino acid configurations of several synthetic peptides, which is the sample type often used when developing characterization approaches. We begin our discussion with a series of common separation-based methods for characterizing endogenous DAACPs within the framework of chiral selection. So as to highlight certain aspects of these measurement approaches, a number of examples of standard peptide separations are included. Following separations, we examine several non-separation measurement techniques: mass spectrometry, nuclear magnetic resonance and peptide digestion.

\section{Non-Chiral Separations}

Many DAACPs were discovered because they possess different properties from the all-L isomers. Intrinsic differences in these peptide diastereomers-pKa values, polarities, hydrodynamic radii-have been exploited in many DAACP separations using high performance liquid chromatography (HPLC), with several widely adopted for capillary electrophoresis (CE).

High Performance Liquid Chromatography-HPLC is the most commonly used separation technique for peptides. Therefore, it should not be surprising that it is the most prevalent method in DAACP investigations, partly owing to its ability to discriminate between diastereomers using non-chiral (such as $\mathrm{C} 18$ ) columns and chiral stationary phase-based columns, its relative low cost, and high throughput. Except for rare cases where diastereomers exhibit similar retention behavior using reversed-phase (RP)-HPLC [12], most known 
DAACPs have been separated using achiral columns in RP-HPLC. Ion-exchange chromatography has also been successful in this application but is not as often used.

A number of research groups have used LC to successfully investigate DAACPs. Kreil et al. [6] showed that deltorphin (YdMFHLMDa), which was produced from the same cDNA of the dermorphin precursor, could be baseline-separated from the L-Met ${ }^{2}$ diastereomer using an RPHPLC column (Fig. 3). Also using this approach, Fujisawa and colleagues [25] separated the molluscan peptide mytilus-FFRFamide (AdLAGDHFFRFa) from seven isomers with a Damino acid at other positions in the peptide. They further confirmed the existence of D-Leu in the native peptide by amino acid analysis; they derivatized the acid hydrolysates and separated the resulting amino acid products using HPLC. The retention of another D-amino acidcontaining neuropeptide isolated from A. fulica, fulicin (FdENFVa), was compared with its all-L isomer and other diastereomers, each with one of the five amino acids substituted with an amino acid in the D-form [43]. Each diastereomer was eluted at different times using an anion-exchange column. Co-elution of native fulicin with synthetic FdENFVa helped to confirm the identity of the peptide. From the same precursor, a fulicin-related peptide, fulyal, was discovered [12]. This study investigated the chromatographic behaviors of fulicin and nine fulicin gene-related peptides (FGRP 1-9) with the all-L-amino acid form and a D-residue in the second position using RP-HPLC. Except for fulicin, which has a similar retention time as its L-isomer, the other FGRP peptide diastereomers were all separated. Additional examples of DAACPs discovered using similar approaches can be found in Table 1. Note that synthetic peptide standards have been used to confirm the identifications.

Also of interest are the experimental parameters that influence separation. Chen et al. [52] examined the effects of mobile phase conditions, temperature, and column packing on the RPHPLC retention behavior of seven peptides derived from the amphipathic peptide AcEAEKAAKEXEKAAKEAEKa, with a position in the middle of the hydrophobic face of the $\alpha$-helix (the ninth residue) representing an L- or a D-amino acid. Proper stationary phase selection is important; for example, when using a Zorbax Eclipse XDB-C8 column, seven model peptides, including three diastereomeric pairs, were baseline separated. At pH 2.0, increasing trifluoroacetic acid or adding sodium perchlorate $\left(\mathrm{NaClO}_{4}\right)$ into the mobile phase improved the peak shape because these compounds acted as hydrophilic anionic ion-pairing reagents; the retention time increased through ion-pairing effects with the positively-charged peptides. Alternatively, using a Zorbax 300 SB-C8 column and increasing temperature from $20^{\circ} \mathrm{C}$ to $65^{\circ} \mathrm{C}$ and $/$ or $80^{\circ} \mathrm{C}$ served to decrease retention time while improving peak shape. This was due to the increased mass-transfer rate of peptides between mobile and stationary phases. Because not all decreases in retention time were proportional, $\mathrm{Q}_{\mathrm{D}}$ (with the $\mathrm{X}$ residue replaced with D-glutamine) and $\mathrm{P}_{\mathrm{L}}$ co-eluted at $80^{\circ} \mathrm{C}$. The two columns showed different selectivity for the following peptide pairs: D,L-Pro, D,L-Ser, and D,L-Gln (at pH 2.0); six peptides were separated at $\mathrm{pH} 7.0$ on both columns.

Capillary Electrophoresis-CE separations are based on charge and molecular shape, and are categorized into several modes [53-55]. Many peptide diastereomers, especially small ones, can be resolved in CE using simple phosphate buffer systems without adding chiral selectors. Enkephalin-related peptides, including two pairs of diastereomers, have been separated using CE [56], with sodium dihydrogen phosphate as the buffer system. A decrease in $\mathrm{pH}$ shortens separation time and improves separation efficiency, and in this case, a $\mathrm{pH}$ slightly higher than 3 was found to be optimal.

A variant of CE is capillary electrochromatography (CEC). Open-tubular CEC, using a C8coated capillary with an aqueous solution of a perfluorinated acid ion-pairing reagent at high concentrations (up to $400 \mathrm{mM}$ ) as background electrolyte, was employed for a novel ioninteraction CE system [57]. A series of synthetic 18-residue, amphipathic alpha-helical peptide 
diastereomers related to Ac-EAEKAAKEAEKAAKEAEKa, with X substituted by $19 \mathrm{~L}$ - or D-amino acids, were used as model peptides. The perfluorinated acid ion-pairing reagent is important for this separation. The same set of model peptides was used to investigate the separation capacities of various CE methods, including capillary zone electrophoresis (CZE), micellar electrokinetic chromatography (MEKC) (with uncoated capillary in the presence of 3-[(3-cholamido-propyl)dimethylammonio]-1-propanesulfonate), and open-tubular CEC (with C8-coated capillary in the presence of 25\% 2,2,2-trifluoroethanol or 25\% ethanol) [58]. The open tubular-CEC methods performed better with peptides containing hydrophilic side chains, and MEKC better separated those containing hydrophobic or aromatic side chains.

\section{Chiral Separations}

Although peptide diastereomers can be discriminated from each other based on differences in a variety of physicochemical properties such as $\mathrm{pKa}$, shape, and hydrophobocity, the use of chiral selectors often makes separations easier. Diastereomeric analytes form transient complexes based on the affinity of the analyte to the chiral selector, and thus result in different retention behaviors or electrophoretic mobilities. The following section focuses on the methods used to separate DAACPs from LAACPs when chiral selectors are employed, highlighting work with both synthetic and natural peptides, and the discussion organized according to separation mode. Chiral selectors are categorized as chiral stationary phases (CSPs) or chiral mobile phase additives (CMPAs), with both used in partition chromatography and CMPAs used in CE. A surprising range of CSPs have been developed, with a large fraction now commercially available. Categories of CSPs include Pirkle-type, cellulose, cyclodextrin, ligand-exchange, crown ethers, glycopeptides, macrocyclic antibiotics, and proteins [59]. The goal is not to include a comprehensive list of diastereomer peptide separations using CSPs and CMPAs from prior work, but rather to include representative examples, first grouped by separation mode and then by type of selector(s) used.

High Performance Liquid Chromatography-While enantiomeric separations require a chiral selector, as described above, diastereomers can be resolved using RP or ion-exchange columns without a chiral additive or stationary phase. The addition of a chiral selector such as a CSP often improves the resolution between peptides and usually does not require peptide derivatization, and therefore has become an effective means of DAACP/LAACP separation. Because the goals of characterizing endogenous DAACPs are often to understand peptide function, and the goals of synthetic DAACP/LAACP separations are to understand and optimize the separation approaches, most comparisons have involved synthetic peptide mixtures. In what follows, several of the more common CSP categories are briefly described in relation to DAACP separations.

Crown ethers, later shown to have significant chiral selectivity, were first introduced by Pederson in 1967 [60], earning him the Nobel Prize in Chemistry in 1987. Crown ethers have become one of the most significant categories of CSPs. While there are a variety of crown ether CSPs, these macrocyclic polyethers all have cavities with chiral selectivity, the inner side of which is lined with oxygen atoms. One of the most widely used, commercially available CSPs, Crownpak CR, was developed by immobilizing (3,3'-diphenyl-1,1'-binaphthyl)-20-crown-6 onto C18 silica gel. Stereoisomers of tripeptide Ala-Ala-Ala have been successfully separated using this column [61]. Another example of a crown ether-based CSP has a tartaric acid unit, for example, (-)-(18-crown-6)-2,3,11,12-tetracarboxylic acid (Fig. 4A) used by Conrad et al. [62] to resolve enantiomers of dipeptides and tripeptides (Fig. 4B). Crown ethers have also been used as the chiral selector added to background electrolyte in CE [63-65], covered later in this review. 
Another common category of CSP includes macrocyclic glycopeptide antibiotics, which were introduced as chiral selectors by Armstrong and co-workers in 1994 [66,67], and first used in thin layer chromatography and CE separations of racemic drugs and amino alcohols. This class of chiral selectors predominantly includes many natural products: vancomycin, teicoplanin and ristocetin A. The anchoring sites on macrocyclic glycopeptides such as amine groups and/or carboxyl groups interact with ionizable groups on analytes and provide the basis for chiral recognition. Interacting forces between the CSP and analytes are mainly hydrogen bonding and $\pi-\pi$ complexation, but depending on the mobile phase system, other interactions such as inclusion complexation and steric interactions can be important [59]. An investigation involving biologically active peptides used 42 peptides from 11 families, including angiotensin, bradykinin, dynorphin, enkephalin, and leucokinin [68]. These were separated on the abovementioned three macrocyclic glycopeptide stationary phases in RP-HPLC using electrospray ionization-MS-compatible mobile phases. Single amino acid substitutions (including chiral residue substitution) were resolved. A series of enkephalin-related peptides with different numbers of D-residues have been separated using this CSP [69]. Those with three or four Damino acids were most retained by the CSP column, with YdAGFdL eluted first among six enkephalin peptides (Fig. 5).

Several ligand-exchange CSPs have been developed, such as those based on a cinchona alkaloid. Separation was achieved via interactions between the chiral selectors and analytes, including ionic attractions, hydrogen bonds, $\pi-\pi$ interactions and steric interactions. A tertbutylcarbamoylquinine CSP was used to separate alanine peptide enantiomers and diastereomers [70]. The four stereoisomers of Ala-Ala dipeptide were separated with four different $\mathrm{N}$-terminal protections. In total, five different $\mathrm{N}$-terminal protections $(3,5-$ dinitrobenzoyl, 2,4-dinitrophenyl, 3,5-dinitrobenzyloxycarbonyl, carbazole-9-carbonyl, and 9-fluorenylmethoxycarbonyl) were examined in terms of their effects on elution order and selectivity. In a follow-up study comparing CSP-based columns with non-chiral RP columns for separating model peptides consisting of Ala oligomers, the cinchona alkaloid derivativebased CSPs demonstrated superior enantiomeric selectivity than diastereoselectivity [71]. All 8 stereoisomers of a tripeptide (Ala-Ala-Ala), and 9 out of 10 stereoisomers of a tetrapeptide (Ala-Ala-Ala-Ala), could be successfully resolved using 2 combined steps.

Another unique category of CSP is the molecularly imprinted polymer (MIP). This type of CSP represents a small-molecule recognition system, produced using the target analyte as template [72]. MIPs were first reported by Polyakov [73-75] in 1931, and are now used as a CSP in chiral separations, working in much the same way a receptor or an antibody recognizes its ligand or antigen. As one example, a non-covalent MIP produced against the template molecule N-Ac-L-Phe-L-Trp-OMe was able to resolve it from the LD-, DL-, and DD-forms, with the template molecule retained longest [76].

As this discussion indicates, because no specific material has been found to be universally applicable for all kinds of peptide separations, a variety of CSPs have been used in enantiomer and diastereomer analysis. While just a few have been discussed here, many others have been reported: cyclodextrins [77,78], polysaccharides [79], synthetic amino acid polymer [80], alpha-chymotrypsin CSP [81], and Pirkle-type CSPs [82].

Capillary Electrophoresis-CE is a small-volume separation approach with high separation efficiency, well suited to separating mass-limited samples such as endogenous peptides. Chiral separations use mobile phase additives added to the background electrolyte. Commonly used CMPAs include cyclodextrins, chiral ion pair complexes, chiral ligandexchange complexes, and others. Because the selector is added to the electrolyte, one can easily optimize the additive composition and concentration, unlike a system that requires a new stationary phase. 
Cyclodextrins are the most common additive employed in CE separations, sometimes used with other additives such as sodium dodecyl sulfate, changing the mode of separation to MEKC. Cyclodextrins are charged chiral molecules with a cavity of appropriate size to interact with an amino acid or peptide, thus modifying the peptide's electrophoretic mobility and allowing a separation. In one report of a peptide separation, diastereomers of aspartyl model dipeptides and tripeptides, including the isomeric iso-Asp-containing beta-peptides, were resolved in untreated fused-silica capillaries as well as polyacrylamide-coated capillaries using negatively charged cyclodextrins as chiral selectors [83]. In another study, acylated Asp-Phe dipeptides, including $\alpha-\mathrm{L}, \mathrm{L}$ parent compound and three other potential Asp-containing stereoisomers ( $\alpha$-D,D, $\alpha$-L,D and $\alpha-\mathrm{D}, \mathrm{L})$, as well as the four iso-Asp-containing stereoisomers ( $\beta$-L,L, $\beta$-D,D, $\beta$-L,D and $\beta$-DL) were separated [84]. Both neutral and charged cyclodextrins were used as CMPAs. Not surprisingly, buffer $\mathrm{pH}$ is an important parameter for optimizing these peptide separations. Oyler et al. [85] separated ten of Atosiban's [1, 1-(3mercaptopropanoic acid)-2-(O-ethyl-D-tyrosine)-4-L-threonine-8-L-ornithine-oxytocin] diastereomers in free solution CE using $100 \mathrm{mM}$ phosphate buffer with $5 \mathrm{mM} \gamma$-cyclodextrin. Without a chiral selector, these peptides do not separate. They compared this approach to hydrophilic interaction chromatography, and found that CE separates fewer peptides but demonstrated a different selectivity. Although endogenous peptide diastereomers have not been separated often, the low-volume advantages of CE were demonstrated by Sheeley et al. [44] in measuring DAACPs from single invertebrate neurons. They developed a method using $\mathrm{CE}$ with laser-induced fluorescence (LIF) and $\gamma$-cyclodextrin as the chiral selector to separate four $\mathrm{D} / \mathrm{L}$ peptide pairs, and investigated the presence of $\mathrm{NdWFa}$, a neuropeptide in Aplysia californica in single cells (Fig. 6).

Several other chiral selectors discussed as CSPs for HPLC applications are used as additives in CE analyses. DL-Leu-DL-Phe and DL-Leu-DL-Leu were baseline separated using the crown ether (+)-18-crown-6-tetracarboxylic acid $\left(18 \mathrm{C}_{6} \mathrm{H}_{4}\right)$ as CMPA, based on different stabilities of the host-guest complexes formed [64]. As another example, Riester et al. [86] reported the successful resolution of eight isomers of YKW peptides by using crown ethers. In some cases, analytes can be derivatized with a reagent (or sometimes a chiral reagent) as this can result in an improved separation versus using chiral selectors alone. The ion-exchange type chiral selector, tert-butylcarbamoylquinine, was incorporated into the background electrolyte and functioned as chiral counter-ion in a stereoselective ion-pair CE system [87]. After derivatizing with 3,5-dinitrobenzoyl (DNB), 2,4-dinitrophenyl, or 3,5-dinitrobenzyloxycarbonyl, four stereoisomers of Ala-Ala were resolved and enantiomers of oligo-Ala peptides up to six amino acids long were also resolved. In a study by Wan and Blomberg [88], separation of chiral diand tri-peptides derivatized with 9-fluorenylmethyl chloroformate were carried out by $\mathrm{CE}$ using vancomycin as a chiral selector. Four isomers of Leu-Leu and two isomers of Ala-GlyGly were separated, and three out of four isomers of Ala-Ala and Leu-Ala were resolved.

Micellar Electrokinetic Chromatography-By adding surfactants into the background electrolyte, $\mathrm{CE}$ can be operated in a different mode with a chromatographic principle, known as MEKC. This mode is not as often used for DAACP/LAACP applications. The examples mentioned here mainly include the use of derivatized peptides. Wan et al. [89] reported the separation of nine peptides with $\gamma$-cyclodextrin as the chiral selector. These peptides were derivatized with 9-fluorenylmethyl chloroformate and subjected to MEKC separations. Two other peptides, Leu-Ala and Leu-Leu, were separated with $\beta$-cyclodextrin after derivatization. With the use of surfactants, separation based on both chiral selectivity and hydrophobicity occurred, resulting in a separation power that chiral selectors alone could not have achieved. In their later work, this same group evaluated the concentration of teicoplanin and acetonitrile on the resolution and retention time of di- and tri-peptide separations [89]. 
Capillary Electrochromatography-Interestingly, the roles of LC and CE in chiral separations are distinct and yet somewhat complementary to each other. CEC can be considered a hybrid of these approaches, as it contains features of both LC and CE and so should be mentioned. In one report, the chiral peptide separation was achieved using a capillary packed with teicoplanin aglycone as a CSP [90]. The diastereomeric dipeptides and tripeptides investigated were baseline-resolved. For these peptides, RP separations worked well, with the organic modifier having an important impact on the separation.

\section{Mass Spectrometry}

While MS can be interfaced with LC and CE separations, the ability to separate DAACPS from LAACPs is based on the differences in elution time offered by the separation. Can MS be used to characterize DAACPs directly? After all, MS is perhaps the detector of choice for peptide characterization as it allows structural characterization of the peptide, including most PTMs and sequences. How does one use MS to determine the chirality of an amino acid residue? Several studies have shown that differences in the chemical properties of two diastereomers can be detected by monitoring the stability of complexes formed with chiral selectors, and that tandem-MS provides different fragmentation results based on the chirality of the amino acid residues.

Perhaps the most obvious approach is to use the same chiral selectors that maximally interact with the peptides during a separation for MS. Chiral recognition with the help of selectors usually depends on noncovalent forces such as hydrogen bonds and van der Waals forces that form between the analyte and chiral selectors. Initial work used crown ethers with fast atom bombardment as the ionization approach [91], and this has been extended to electrospray ionization (ESI) [91] and matrix-assister laser desorption/ionization [92]. Specifically, Jorgensen et al. [93] used vancomycin with ESI on a triple-quadrupole instrument. The complex intensities of the (L,D,D)- and (L,L,L)-stereoisomers of diacetyl-Lys-Ala-Ala, the latter being isotopically labeled, were monitored by single-stage MS, and selective binding of vancomycin to the (L,D,D)-isomer was observed. This result was in good agreement with those from solution phase experiments. A later report used antibiotics with collisionally-induced dissociation (CID) to investigate complexes of the antibiotics with tripeptides [94]. This work demonstrated a loss of specific binding between the antibiotics and the peptides when the two $\mathrm{D}$-Ala residues located at the $\mathrm{C}$-terminus were replaced with their $\mathrm{L}$-configured isomers.

At times referred to as the kinetic method, exchange reactions have been used to monitor the stability of analyte-chiral selector complexes. This approach helped to discriminate four enantiomers of Ser-His-OMe, with a hydroxyl group and an imidazole group in the side chain [95] (Fig. 7). Two analyte enantiomers form complexes with copper chloride and a chiral reference compound (denoted as ref* in the figure) in solution, and competitive CID occurs to form the dimeric complexes by loss of ref* or the analyte, respectively. The potentially different stabilities of the diastereomeric ions are reflected by different abundances of the fragment ions relative to that of a common fragment. Experimental abundance ratios were used to determine the enantiomeric composition of the analyte, provided a calibration curve is obtained beforehand. Lagarrigue et al. [96] used CuII and FeII as transition metal ions to differentiate the diastereomeric pentapeptides YAGFL, YDAGFL and YDAGFDL by ESI-ion trap MS. Dissociation rate constants under low-energy CID process of the complexes formed between peptides and metal ions are dependent on their stabilities resulting from different steric interactions.

It is also possible to characterize DAACPs and other peptides without using chiral selectors, usually by examining the molecular fragmentation in tandem-MS spectra. Intrinsic differences among diastereomers are the basis for this type of characterization. Some pioneer studies include Mammoliti et al. [97], who demonstrated that Z-blocked Phe-Phe and Ala-Phe 
diastereomers differed in their decarboxylation behaviors through competing pathways. The different kinetic energy released from these decarboxylation reactions allowed the diastereomers to be discriminated from each other. Using unimolecular decomposition, another study showed that different diastereomers had different product ion abundances [98].

Tsunematsu et al. [99] assessed the differentiation of diastereomers of BOC-protected Pro-Pro by studying the sodium adduct ions with both single-stage and tandem MS. Adams et al. [100] distinguished diastereomers of Trp-cage peptide (NLYIQWLKDGGPSSGRPPPS) by electron capture dissociation. The fragmentation pattern reflects differences in the stability of the gas-phase tertiary protein structure with a D-amino acid substitution. The chiral selectivity was diminished at higher temperature when the tertiary structure was degraded, and was also reduced at higher charge states where ionic interactions largely destroyed the neutral hydrogen bonding needed for chiral recognition. Tandem MS experiments using CID did not allow differentiation between diastereomers using fragment ratios; however, substantially different stabilities of the parent ions were noted. The same group completed another interesting investigation by adapting the kinetic method to quantify the differences between fragmentation patterns of stereoisomeric peptides by measuring fragment ion abundances [101] (Fig. 8). Dermorphin and related peptides were discriminated and quantitatively measured.

Five epimers of the pentapeptide, GLSFA, were discriminated by their different collisionally activated dissociation (CAD) patterns. Ratios of fragment ion abundances between stereoisomers have been measured [102] and the values were as high as 3.8, meaning the configuration of stereoisomer pairs was dramatically different. Stereochemical effects were also demonstrated using $\omega$-agatoxins IVB and $-\mathrm{C}$, and diprotonated peptide

LVFFAEDVGSNK, a tryptic fragment from the amyloid $\beta$-protein. We expect such approaches to become more common.

\section{Nuclear Magnetic Resonance}

NMR can determine the three dimensional structure of a peptide and so can be used to resolve the chirality of peptide residues. Typically used to study molecular interactions between analytes such as peptides and chiral selectors [103-105], it does not appear that NMR has been used for DAACP peptide discovery as yet, partially because of its intrinsic low sensitivity compared to the separations- and MS-based approaches. It also has been applied to studying peptide-receptor interactions [106] and will become an indispensable tool to examine the differences in interactions between an endogenous DAACP and an LAACP with their cognate receptors. As one example of the use of NMR, achatin-I (GdFAD), isolated from A. fulica, was found to have different chromatographic behavior from its all-L isomer. An ${ }^{1} \mathrm{H}-\mathrm{NMR}$ spectral study demonstrated the points of interaction as the $\alpha$-methine proton of the phenylalanine with the $\alpha$-methane proton and the methyl protons of alanine in achatin-I appearing upfield from the L-isomer. In another interesting study from the peptide toxin field [22], an NMR experiment demonstrated the necessity of having a D-Phe13 in the conotoxin peptide, conomarphin, for forming a tight loop in the middle of the peptide. The toxin counterpart with L-Phe13 did not form this loop, perhaps indicating the reason why a D-Phe is required to obtain the specific functions of this peptide.

\section{Peptide Digestion}

Acid Hydrolyzation-In multiple instances of DAACP discovery, acid hydrolysis followed by derivatization and separation is common because the separation of amino acid enantiomers is a relatively mature technique. The limited number of possible amino acids makes the analysis of peptide hydrolysates more convenient. As a classic example, to confirm that [D-Leu2] deltorphin was a DAACP, the peptide was first hydrolyzed, amino acids derivatized with a chiral reagent, 1-fluoro-2,4-dinitro-5-L-alanine and separated by RP-HPLC, and configuration 
of each residue determined [7,107]. In a study focusing on beta-amyloid peptides from Alzheimer's disease patients, the peptides were digested, the resulting amino acids derivatized with the chiral reagent (+)- or (-)-1-(9-anthryl)-2-propyl chloroformate, and subsequently separated using MEKC [108]. The high separation efficiency of the MEKC-LIF system, yielding approximately a million theoretical plates $/ \mathrm{m}$ for most amino acids, facilitated the simultaneous chiral determination of nine amino acids. Samples analyzed include 1-40 betaamyloid peptides, in vitro precipitated beta-amyloid fibrils, and human senile plaque samples. As another example, Liu et al. [109] derivatized peptides and amino acids with 4-(3isothiocyanatopyrrolidinl-yl)-7-nitro-2,1,3-benzoxadiazole [R-(-)- or S-(+)-NBD-PyNCS] and characterized the resulting diastereomeric derivatives using CE; they characterized the Damino acids in the peptide gramicidin D after applied acid hydrolysis.

Amino acid analysis after acid hydrolysis itself does not generate sequence information for the peptides; therefore, sequencing approaches such as Edman degradation and tandem-MS are usually employed. Simultaneous sequencing combines Edman degradation methods and a derivatizing reagent; thus, residues freed from the peptide can be immediately converted to identifiable units [110]. Using this technique, a group of hydrophobic peptides discovered in $B$. variegata were found to contain a D-alloisoleucine residue in the second position [10]. Separation of TZ-amino acids generated in an Edman procedure can be separated on a CSP ( $\beta$-cyclodextrin); chiral Edman reagents were introduced by Toyo'oka and Liu in 1995 [111]. Kurosu et al. [112] demonstrated optical resolution of phenylthiohydantoin amino acids by CE and identification of the phenylthiohydantoin-D-amino acid residue of [D-Ala $\left.{ }^{2}\right]$-methionine enkephalin.

Enzyme Digestion-DAACPs are obviously functionally important, either because they have different receptor binding or a different lifetime due to a greater resistance to common peptidases. One can turn these biologically important differences into a method of characterizing the DAACPs. In fact, the enzymatic approach is among the earliest used for determining DAACPs.

Lipmann et al. [4] developed the enzymatic method in 1940 to identify the presence of Damino acids in a small sample. In this pioneering work, they used D-amino acid oxidase to act on hydrolysates because this enzyme selectively digests D-amino acids instead of L-residues; they measured oxygen consumption and ammonia production to determine the substrate configuration. This method was later employed by Montecucchi et al. [5] in discovering dermorphin in 1981 and Erspamer et al. [9] in finding deltorphins I and II. Specifically, the presence of D-alanine in [D-Ala ${ }^{2}$ deltorphins (YdAFD, YdAFE), isolated from skin extracts of Phyllomedusa bicolor, was demonstrated by using D-amino acid oxidase on acid hydrolysates of the peptides; the disappearance of this amino acid species indicated it is in the D-form [9].

Another enzyme that has been used to assist DAACP discovery is aminopeptidase M. This enzyme cleaves $\mathrm{N}$-terminal L-amino acids off peptides but won't digest D-amino acids. In a recent study, Ewing et al. [113] used this enzyme to screen for DAACPs by taking a nervous system extract, and dividing it into two samples, one of which was digested with the enzyme; both fractions were then subject to LC-MS (Fig. 9). This study observed that peptides that were not digested were more likely to be DAACPs, and those that disappeared after exposure to the enzyme were more likely to be composed solely of L-amino acids. As a proof of concept, after digestion of the abdominal ganglia extract of $A$. californica, the known DAACP, NdWFa, was characterized. Several additional peptides were shown to be resistant to the enzymatic digestion; it will be interesting to see if these are unknown DAACPs. 


\section{FUTURE DIRECTIONS}

Peptidomics, the global characterization of peptides, whether toxins, neuropeptides or even serum-peptides, is an area that is receiving greater and greater attention. These studies aim to characterize the peptide complement, including PTMs, in complex samples such as a brain tissue. With the addition of an L-to-D switch in the configuration of an amino acid in a peptide now considered as a possible PTM, achieving complete characterization of endogenous peptides is a more complex endeavor. Certainly, new methods are required to accomplish such measurements and represent one future direction of peptidomic research. As outlined in this review, a variety of analytical techniques are currently capable of separating and characterizing the configuration of amino acids in a peptide. To date, however, most approaches have worked with synthetic peptides and relatively simple mixtures. We expect that further refinements will continue, and that approaches will be developed that can handle hundreds to thousands of peptides. Some approaches will be survey-based, enabling one to determine which peptides in a mixture are putative DAACPs, and others will allow preselected peptides to be evaluated. Only by implementing both approaches will questions on the prevalence and function of this elusive PTM be addressed. We certainly expect the range of analytical methods used to evaluate chirality to expand as improved separations and new enzymatic approaches are reported. Hopefully, in the future, the enzymes responsible for these transformations will be known, allowing specific tissues containing the appropriate enzymes to be targeted for DAACP characterization.

\section{Acknowledgments}

This material is based upon work supported by the National Science Foundation under Award No. CHE-04-00768, the National Institutes of Health under Award No. NS031069 and the National Institute of Drug Abuse under Award No. DA018310 to the UIUC Neuroproteomics Center on Cell-Cell Signaling.

\section{REFERENCES}

1. D'Aniello A, Lee JM, Petrucelli L, et al. Regional decreases of free D-aspartate levels in Alzheimer's disease. Neurosci Lett 1998;250:131-134. [PubMed: 9697936]

2. Fuchs SA, Berger R, Klomp LWJ, et al. D-amino acids in the central nervous system in health and disease. Mol Genet Metab 2005;85:168-180. [PubMed: 15979028]

3. Snyder SH, Ferris CD. Novel neurotransmitters and their neuropsychiatric relevance. Am J Psychiatry 2000;157:1738-1751. [PubMed: 11058466]

4. Lipmann F, Hotchkiss RD, Dubos RJ. The occurrence of D-amino acids in gramicidin and tyrocidine. J Biol Chem 1941;141:163-169.

5. Montecucchi PC, Decastiglione R, Piani S, et al. Amino-acid-composition and sequence of dermorphin, a novel opiate-like peptide from the skin of Phyllomedusa sauvagei. Int J Pept Protein Res 1981;17:275-283. [PubMed: 7287299]

6. Kreil G, Barra D, Simmaco M, et al. Deltorphin, a novel amphibian skin peptide with high selectivity and affinity for delta-opioid receptors. Eur J Pharmacol 1989;162:123-128. [PubMed: 2542051]

7. Barra D, Mignogna G, Simmaco M, et al. [d-leu(2)]deltorphin, a 17 amino-acid opioid peptide from the skin of the brazilian hylid frog, Phyllomedusa-burmeisteri. Peptides 1994;15:199-202. [PubMed: 8008623]

8. Mor A, Delfour A, Sagan S, et al. Isolation of dermenkephalin from amphibian skin, a high-affinity delta-selective opioid heptapeptide containing a d-amino-acid residue. FEBS Lett 1989;255:269-274. [PubMed: 2551734]

9. Erspamer V, Melchiorri P, Falconierierspamer G, et al. Deltorphins: a family of naturally-occurring peptides with high-affinity and selectivity for delta-opioid binding-sites. Proc Natl Acad Sci USA 1989;86:5188-5192. [PubMed: 2544892] 
10. Mignogna G, Simmaco M, Kreil G, et al. Antibacterial and hemolytic peptides containing Dalloisoleucine from the skin of Bombina variegata. EMBO J 1993;12:4829-4832. [PubMed: 8223491]

11. Kamatani Y, Minakata H, Kenny PTM, et al. Achatin-I, an endogenous neuroexcitatory tetrapeptide from Achatina fulica Férussac containing a D-amino acid residue. Biochem Biophys Res Commun 1989;160:1015-1020. [PubMed: 2597281]

12. Yasuda-Kamatani Y, Kobayashi M, Yasuda A, et al. A novel D-amino acid-containing peptide, fulyal, coexists with fulicin gene-related peptides in Achatina atria. Peptides 1997;18:347-354. [PubMed: 9145419]

13. Morishita F, Nakanishi Y, Kaku S, et al. A novel D-amino-acid-containing peptide isolated from Aplysia heart. Biochem Biophys Res Commun 1997;240:354-358. [PubMed: 9388481]

14. Jimenez EC, Olivera BM, Gray WR, et al. Contryphan is a D-tryptophan-containing Conus peptide. J Biol Chem 1996;271:28002-28005. [PubMed: 8910408]

15. Jimenez EC, Craig AG, Watkins M, et al. Bromocontryphan: post-translational bromination of tryptophan. Biochemistry 1997;36:989-994. [PubMed: 9033387]

16. Jacobsen R, Jimenez EC, Grilley M, et al. The contryphans, a D-tryptophan-containing family of Conus peptides: interconversion between conformers. J Pept Res 1998;51:173-179. [PubMed: 9531419]

17. Jacobsen RB, Jimenez EC, De la Cruz RGC, et al. A novel D-leucine-containing Conus peptide: diverse conformational dynamics in the contryphan family. J Pept Res 1999;54:93-99. [PubMed: 10461743]

18. Buczek O, Yoshikami D, Watkins M, et al. Characterization of D-amino-acid-containing excitatory conotoxins and redefinition of the I-conotoxin superfamily. FEBS J 2005;272:4178-4188. [PubMed: 16098199]

19. Buczek O, Yoshikami D, Bulaj G, et al. Post-translational amino acid isomerization: a functionally important D-amino acid in an excitatory peptide. J Biol Chem 2005;280:4247-4253. [PubMed: 15561705]

20. Buczek O, Jimenez EC, Yoshikami D, et al. I-1-superfamily conotoxins and prediction of single Damino acid occurrence. Toxicon 2008;51:218-229. [PubMed: 17996262]

21. Dutertre S, Lumsden NG, Alewood PF, et al. Isolation and characterisation of conomap-Vt, a Damino acid containing excitatory peptide from the venom of a vermivorous cone snail. FEBS Lett 2006;580:3860-3866. [PubMed: 16797543]

22. Han YH, Huang FJ, Jiang H, et al. Purification and structural characterization of a D-amino acidcontaining conopeptide, conomarphin, from Conus marmoreus. FEBS J 2008;275:1976-1987. [PubMed: 18355315]

23. Pisarewicz K, Mora D, Pflueger FC, et al. Polypeptide chains containing D-gamma-hydroxyvaline. J Am Chem Soc 2005;127:6207-6215. [PubMed: 15853325]

24. Iwakoshi E, Hisada M, Minakata H. Cardioactive peptides isolated from the brain of a Japanese octopus, Octopus minor. Peptides 2000;21:623-630. [PubMed: 10876044]

25. Fujisawa Y, Ikeda T, Nomoto K, et al. The FMRFamide-related decapeptide of Mytilus contains a D-amino acid residue. Comp Biochem Physiol C Pharmacol Toxicol Endocrinol 1992;102:91-95.

26. Soyez D, Vanherp F, Rossier J, et al. Evidence for a conformational polymorphism of invertebrate neurohormones. D-amino acid residue in crustacean hyperglycemic peptides. J Biol Chem 1994;269:18295-18298. [PubMed: 8034574]

27. Yasuda A, Yasuda Y, Fujita T, et al. Characterization of crustacean hyperglycemic hormone from the crayfish (Procambarus clarkii): multiplicity of molecular forms by stereoinversion and diverse functions. Gen Comp Endocrinol 1994;95:387-398. [PubMed: 7821776]

28. Heck SD, Kelbaugh PR, Kelly ME, et al. Disulfide bond assignment of omega-Agatoxin IVB and omega-Agatoxin IVC: discovery of a D-serine residue in omega-Agatoxin IVB. J Am Chem Soc 1994;116:10426-10436.

29. Torres AM, Menz I, Alewood PF, et al. D-amino acid residue in the C-type natriuretic peptide from the venom of the mammal, Ornithorhynchus anatinus, the Australian platypus. FEBS Lett 2002;524:172-176. [PubMed: 12135762] 
30. Torres AM, Tsampazi C, Geraghty DP, et al. D-amino acid residue in a defensin-like peptide from platypus venom: effect on structure and chromatographic properties. Biochem J 2005;391:215-220. [PubMed: 16033333]

31. Broccardo M, Erspamer V, Falconierierspamer G, et al. Pharmacological data on dermorphins, a new class of potent opioid-peptides from amphibian skin. Br J Pharmacol 1981;73:625-631. [PubMed: 7195758]

32. Kreil G. D-amino acids in animal peptides. Annu Rev Biochem 1997;66:337-345. [PubMed: 9242910]

33. Iida T, Santa T, Toriba A, et al. Amino acid sequence and D/L-configuration determination methods for D-amino acid-containing peptides in living organisms. Biomed Chromatogr 2001;15:319-327. [PubMed: 11507713]

34. Li L, Sweedler JV. Peptides in the brain: mass spectrometry-based measurement approaches and challenges. Annu Rev Anal Chem 2008;1:451-483.

35. Hummon AB, Richmond TA, Verleyen P, et al. From the genome to the proteome: uncovering peptides in the Apis brain. Science 2006;314:647-649. [PubMed: 17068263]

36. Fricker LD, Lim J, Pan Ha, et al. Peptidomics: identification and quantification of endogenous peptides in neuroendocrine tissues. Mass Spectrom Rev 2006;25:327-344. [PubMed: 16404746]

37. Svensson M, Skold K, Nilsson A, et al. Neuropeptidomics: expanding proteomics downwards. Biochem Soc Trans 2007;35:588-593. [PubMed: 17511658]

38. Gevers W, Kleinkauf H, Lipmann F. Peptidyl transfers in Gramicidin S biosynthesis from enzymebound thioester intermediates. Proc Natl Acad Sci USA 1969;63:1335-1342. [PubMed: 5260936]

39. Schnell N, Entian KD, Schneider U, et al. Prepeptide sequence of epidermin, a ribosomally synthesized antibiotic with 4 sulfide-rings. Nature 1988;333:276-278. [PubMed: 2835685]

40. Kaletta C, Entian KD, Jung G. Prepeptide sequence of cinnamycin (Ro 09-0198): the first structural gene of a duramycin-type lantibiotic. Eur J Biochem 1991;199:411-415. [PubMed: 2070795]

41. Kreil G. Conversion of L- to D-amino acids: a posttranslational reaction. Science 1994;266:996-997. [PubMed: 7973683]

42. Csordas A, Michl H. Isolation and structure of a hemolytic polypeptide from defensive secretion of European Bombina species. Monatsh Chem 1970;101:182.

43. Ohta N, Kubota I, Takao T, et al. Fulicin, a novel neuropeptide containing a D-amino-acid residue isolated from the ganglia of Achatina fulica. Biochem Biophys Res Commun 1991;178:486-493. [PubMed: 1859408]

44. Sheeley SA, Miao H, Ewing MA, et al. Measuring D-amino acid-containing neuropeptides with capillary electrophoresis. Analyst 2005;130:1198-1203. [PubMed: 16021220]

45. Heck SD, Faraci WS, Kelbaugh PR, et al. Posttranslational amino acid epimerization: enzymecatalyzed isomerization of amino acid residues in peptide chains. Proc Natl Acad Sci USA 1996;93:4036-4039. [PubMed: 8633012]

46. Shikata Y, Watanabe T, Teramoto T, et al. Isolation and characterization of a peptide isomerase from funnel-web spider venom. J Biol Chem 1995;270:16719-16723. [PubMed: 7622482]

47. Torres AM, Tsampazi M, Tsampazi C, et al. Mammalian L-to-D-amino-acid-residue isomerase from platypus venom. FEBS Lett 2006;580:1587-1591. [PubMed: 16480722]

48. Bansal PS, Torres AM, Crossett B, et al. Substrate specificity of platypus venom L-to-D-peptide isomerase. J Biol Chem 2008;283:8969-8975. [PubMed: 18158286]

49. Gallois D, Brisorgueil MJ, Conrath M, et al. Posttranslational isomerization of a neuropeptide in crustacean neurosecretory cells studied by ultrastructural immunocytochemistry. Eur J Cell Biol 2003;82:431-440. [PubMed: 14533741]

50. Fricker LD. Minireview: neuropeptidomics to study peptide processing in animal models of obesity. Endocrinology 2007;148:4185-4190. [PubMed: 17584973]

51. Svensson M, Skold K, Nilsson A, et al. Neuropeptidomics: MS applied to the discovery of novel peptides from the brain. Anal Chem 2007;79:14-21.

52. Chen Y, Mant CT, Hodges RS. Selectivity differences in the separation of amphipathic alpha-helical peptides during reversed-phase liquid chromatography at $\mathrm{pHs} 2.0$ and 7.0: effects of different packings, mobile phase conditions and temperature. J Chroma A 2004;1043:99-111. 
53. Landers, JP. Handbook of capillary electrophoresis. Boca Raton, FL, USA: CRC Press Inc.; 1996.

54. Terabe S. Micellar electrokinetic chromatography for high-performance analytical separation. Chem Rec 2008;8:291-301. [PubMed: 18956478]

55. Kostal V, Katzenmeyer J, Arriaga EA. Capillary electrophoresis in bioanalysis. Anal Chem 2008;80:4533-4550. [PubMed: 18484738]

56. Huang Y, Duan JP, Jiang XY, et al. Separation and determination of enkephalin-related peptides using capillary electrophoresis. J Sep Sci 2005;28:2534-2539. [PubMed: 16405185]

57. Popa TV, Mant CT, Hodges RS. Capillary electrophoresis of amphipathic alpha-helical peptide diastereomers. Electrophoresis 2004;25:94-107. [PubMed: 14730573]

58. Popa TV, Mant CT, Chen Y, et al. Capillary zone electrophoresis of alpha-helical diastereomeric peptide pairs with anionic ion-pairing reagents. J Chroma A 2004;1043:113-122.

59. Subramanian, G. Chiral separation techniques: a practical approach. Weinheim, Germany: WileyVCH; 2007.

60. Pederson CJ. Cyclic polyethers and their complexes with metal salts. J Am Chem Soc 1967;89:7017.

61. Esquivel B, Nicholson L, Peerey L, et al. Enantiomeric resolution of underivatized small peptides by HPLC with a chiral crown-ether stationary phase. J High Resolut Chromatogr 1991;14:816-823.

62. Conrad U, Chankvetadze B, Scriba GKE. High performance liquid chromatographic separation of dipeptide and tripeptide enantiomers using a chiral crown ether stationary phase. J Sep Sci 2005;28:2275-2281. [PubMed: 16342791]

63. Kuhn R, Erni F, Bereuter T, et al. Chiral recognition and enantiomeric resolution based on host-guest complexation with crown ethers in capillary zone electrophoresis. Anal Chem 1992;64:2815-2820.

64. Schmid MG, Gubitz G. Capillary zone electrophoretic separation of the enantiomers of dipeptides based on host-guest complexation with a chiral crown ether. J Chroma A 1995;709:81-88.

65. Mori Y, Ueno K, Umeda T. Enantiomeric separations of primary amino compounds by non-aqueous capillary zone electrophoresis with a chiral crown ether. J Chromatogr A 1997;757:328-332.

66. Armstrong DW, Rundlett KL, Chen JR. Evaluation of the macrocyclic antibiotic vancomycin as a chiral selector for capillary electrophoresis. Chirality 1994;6:496-509. [PubMed: 7946976]

67. Armstrong DW, Zhou YW. Use of a macrocyclic antibiotic as the chiral selector for enantiomeric separations by TLC. J Liq Chromatogr 1994;17:1695-1707.

68. Zhang B, Soukup R, Armstrong DW. Selective separations of peptides with sequence deletions, single amino acid polymorphisms, and/or epimeric centers using macrocyclic glycopeptide liquid chromatography stationary phases. J Chromatogr A 2004;1053:89-99. [PubMed: 15543975]

69. Soukup-Hein RJ, Schneiderheinze J, Mehelic P, et al. LC and LC-MS separation of peptides on macrocyclic gly copeptide stationary phases: diastereomeric series and large peptides.

Chromatographia 2007;66:461-468.

70. Czerwenka C, Lammerhofer M, Lindner W. Micro-HPLC and standard-size HPLC for the separation of peptide stereoisomers employing an ion-exchange principle. J Pharm Biomed Anal 2003;30:17891800. [PubMed: 12485720]

71. Czerwenka C, Maier NM, Lindner W. Liquid chromatographic-mass spectrometric separation of oligoalanine peptide stereoisomers: influence of absolute configuration on enantioselectivity and two-dimensional separation of diastereomers and enantiomers. J Chromatogr A 2004;1038:85-95. [PubMed: 15233524]

72. Maier NM, Lindner W. Chiral recognition applications of molecularly imprinted polymers: a critical review. Anal Bioanal Chem 2007;389:377-397. [PubMed: 17632705]

73. Polyakov MV. Adsorption properties and structure of silica gel. Russ J Phys Chem 1931:2.

74. Polyakov MV, M SP, W PM, et al. On the structure of silica. Russ J Phys Chem 1933;4:454-456.

75. Polyakov MV, P KL, E NI. On the dependence of silica gel adsorption properties on the character of its porosity. Russ J Phys Chem 1937;10:100-112.

76. Kempe M, Mosbach K. Chiral recognition of N-alpha-protected amino acids and derivatives in noncovalently molecularly imprinted polymers. Int J Pept Protein Res 1994;44:603-606. [PubMed: 7705983]

77. Armstrong DW, Chen S, Chang C, et al. A new approach for the direct resolution of racemic betaadrenergic blocking-agents by HPLC. J Liq Chromatogr 1992;15:545-556. 
78. Chen S. The facile HPLC enantioresolution of amino acids, peptides on naphthylethylcarbamatebeta-cyclodextrin bonded phases using the acetonitrile-based mobile phase after their pre-column derivatization with phenyl isothiocyanate: factors that affect the resolution. Amino Acids 2004;26:291-298. [PubMed: 15221510]

79. Lin SL, Chen ST, Wu SH, Wang KT. Separation of aspartame and its precursor stereoisomers by chiral chromatography. J Chromatogr 1991;540:392-396.

80. Nakano T. Optically active synthetic polymers as chiral stationary phases in HPLC. J Chromatogr A 2001;906:205-225. [PubMed: 11215889]

81. Jadaud P, Wainer IW. Stereochemical recognition of enantiomeric and diastereomeric dipeptides by high-performance liquid chromatography on a chiral stationary phase based upon immobilized alphachymotrypsin. J Chromatogr 1989;476:165-174. [PubMed: 2777971]

82. Pirkle WH, Alessi DM, Hyun MH, et al. Separation of some enantiomeric dipeptides and tripeptides on chiral stationary phases. J Chromatogr 1987;398:203-209. [PubMed: 3654838]

83. Sabah S, Scriba GKE. Electrophoretic stereoisomer separation of aspartyl dipeptides and tripeptides in untreated fused-silica and polyacrylamide-coated capillaries using charged cyclodextrins. J Chromatogr A 1998;822:137-145.

84. Skanchy DJ, Wilson R, Poh T, et al. Resolution of acylated dipeptide stereoisomers by capillary electrophoresis using sulfobutylether derivatized beta-cyclodextrin. Electrophoresis 1997;18:985995. [PubMed: 9221888]

85. Oyler AR, Armstrong BL, Cha JY, et al. Hydrophilic interaction chromatography on amino-silica phases complements reversed-phase high-performance chromatography and capillary electrophoresis for peptide analysis. J Chromatogr A 1996;724:378-383.

86. Riester D, Wiesmuller KH, Stoll D, et al. Racemization of amino acids in solid-phase peptide synthesis investigated by capillary electrophoresis. Anal Chem 1996;68:2361-2365. [PubMed: 8686928]

87. Czerwenka C, Lammerhofer M, Lindner W. Electrolyte and additive effects on enantiomer separation of peptides by nonaqueous ion-pair capillary electrophoresis using tert.-butylcarbamoylquinine as chiral counterion. Electrophoresis 2002;23:1887-1899. [PubMed: 12116133]

88. Wan H, Blomberg LG. Enantiomeric separation by capillary electrophoresis of di- and tri-peptides derivatized with 9-fluorenylmethyl chloroformate using vancomycin as chiral selector. J Microcolumn Sep 1996;8:339-344.

89. Wan H, Blomberg LG. Enantiomeric and diastereomeric separation of di- and tripeptides by capillary electrophoresis. J Chromatogr A 1997;758:303-311.

90. Schmid MG, Grobuschek N, Pessenhofer V, et al. Chiral resolution of diastereomeric di- and tripeptides on a teicoplanin aglycone phase by capillary electrochromatography. Electrophoresis 2003;24:2543-2549. [PubMed: 12900866]

91. Sawada M, Takai Y, Yamada H, et al. Chiral recognition in host-guest complexation determined by the enantiomer-labeled guest method using fast atom bombardment mass spectrometry. J Am Chem Soc 1995;117:7726-7736.

92. So MP, Wan TS, Chan TW. Differentiation of enantiomers using matrix-assisted laser desorption/ ionization mass spectrometry. Rapid Commun Mass Spectrom 2000;14:692-695. [PubMed: 10786909]

93. Jorgensen TJD, Roepstorff P, Heck AJR. Direct determination of solution binding constants for noncovalent complexes between bacterial cell wall peptide analogues and vancomycin group antibiotics by electrospray ionization mass spectrometry. Anal Chem 1998;70:4427-4432.

94. Jorgensen TJD, Delforge D, Remacle J, et al. Collision-induced dissociation of noncovalent complexes between vancomycin antibiotics and peptide ligand stereoisomers: evidence for molecular recognition in the gas phase. Int J Mass Spectrom 1999;188:63-85.

95. Chen J, Zhu CJ, Chen Y, et al. Enantiomeric quantification of the bioactive peptide seryl-histidine methyl ester by electrospray ionization mass spectrometry and the kinetic method. Rapid Commun Mass Spectrom 2002;16:1251-1253. [PubMed: 12112280]

96. Lagarrigue M, Bossee A, Afonso C, et al. Diastereomeric differentiation of peptides with CuII and FeII complexation in an ion trap mass spectrometer. J Mass Spectrom 2006;41:1073-1085. [PubMed: 16888715] 
97. Mammoliti E, Sindona G, Uccella N. Characterization of Z-blocked isomeric dipeptides by fast atom bombardment tandem mass spectrometry and kinetic energy release measurements. Org Mass Spectrom 1992;27:495-501.

98. Schwartz BL, Erickson BW, Bursey MM, et al. Dependence of benzyl alcohol loss on C-terminal amino acid in tandem mass spectrometry of N-protected tripeptides. Org Mass Spectrom 1993;28:1053-1058.

99. Tsunematsu H, Ikeda H, Hanazono H, et al. Differentiation of a pair of diastereomeric tertiarybutoxycarbonylprolylproline ethyl esters by collision-induced dissociation of sodium adduct ions in electrospray ionization mass spectrometry and evidence for chiral recognition by ab initio molecular orbital calculations. J Mass Spectrom 2003;38:188-195. [PubMed: 12577285]

100. Adams CM, Kjeldsen F, Zubarev RA, et al. Electron capture dissociation distinguishes a single Damino acid in a protein and probes the tertiary structure. J Am Soc Mass Spectrom 2004;15:10871098. [PubMed: 15234367]

101. Adams CM, Zubarev RA. Distinguishing and quantifying peptides and proteins containing D-amino acids by tandem mass spectrometry. Anal Chem 2005;77:4571-4580. [PubMed: 16013875]

102. Serafin SV, Maranan R, Zhang KL, et al. Mass spectrometric differentiation of linear peptides composed of L-amino acids from isomers containing one D-amino acid residue. Anal Chem 2005;77:5480-5487. [PubMed: 16131056]

103. Rekharsky MV, Yamamura H, Kawai M, et al. Complexation and chiral recognition thermodynamics of gamma-cyclodextrin with $\mathrm{N}$-acetyl- and $\mathrm{N}$-carbobenzyloxy-dipeptides possessing two aromatic rings. J Org Chem 2003;68:5228-5235. [PubMed: 12816482]

104. Suss F, Kahle C, Holzgrabe U, et al. Studies on the chiral recognition of peptide enantiomers by neutral and sulfated beta-cyclodextrin and heptakis-(2,3-di-O-acetyl)-beta-cyclodextrin using capillary electrophoresis and nuclear magnetic resonance. Electrophoresis 2002;23:1301-1307. [PubMed: 12007130]

105. Kano K, Hasegawa H, Miyamura M. Chiral recognition of dipeptide methyl esters by an anionic beta-cyclodextrin. Chirality 2001;13:474-482. [PubMed: 11466771]

106. Edison AS, Espinoza E, Zachariah C. Conformational ensembles: the role of neuropeptide structures in receptor binding. J Neurosci 1999;19:6318-6326. [PubMed: 10414961]

107. Scaloni A, Simmaco M, Bossa F. Determination of the chirality of amino acid residues in the course of subtractive Edman degradation of peptides. Anal Biochem 1991;197:305-310. [PubMed: 1785683]

108. Thorsen G, Bergquist J, Westlind-Danielsson A, et al. Stereoselective determination of amino acids in beta-amyloid peptides and senile plaques. Anal Chem 2001;73:2625-2631. [PubMed: 11403309]

109. Liu YM, Schneider M, Sticha CM, et al. Separation of amino acid and peptide stereoisomers by nonionic micelle-mediated capillary electrophoresis after chiral derivatization. J Chromatogr A 1998;800:345-354. [PubMed: 9561768]

110. Scaloni A, Simmaco M, Bossa F. Determination of the chirality of amino acid residues in the course of subtractive edman degradation of peptides. Anal Biochem 1991;197:305-310. [PubMed: 1785683]

111. Toyo'oka T, Suzuki T, Watanabe T, et al. Sequential analysis of D/L-amino acid in peptide with a novel chiral Edman degradation method. Anal Sci 1996;12:779-782.

112. Kurosu Y, Murayama K, Shindo N, et al. Optical resolution of phenylthiohydantoin amino acids by capillary electrophoresis and identification of the phenylthiohydantoin-D-amino acid residue of [DAla(2)]-methionine enkephalin. J Chromatogr A 1996;752:279-286. [PubMed: 8962502]

113. Ewing MA, Wang J, Sheeley SA, et al. Detecting D-Amino acid-containing neuropeptides using selective enzymatic digestion. Anal Chem 2008;80:2874-2880. [PubMed: 18341354]

114. Aplysia. Photo by Genny Anderson;

115. Platypus. Photo from Wikipedia; [Accessed January 26, 2009]. The Free Encyclopedia. Available at: 〈http://en.wikipedia.org/w/index.php?title=Platypus\&oldid=266509447>

116. Lobster. Photo from Wikipedia; [Accessed January 26, 2009]. The Free Encyclopedia. Available at: http://en.wikipedia.org/w/index.php?title=Homarus\&oldid=248439950

117. Spider. Photo courtesy of Spider Pharm. Inc; 
118. Frog. Photo from Wikipedia; [Accessed January 26, 2009]. The Free Encyclopedia. Available at: http://en.wikipedia.org/w/index.php?title=Phyllomedusa\&oldid=260740026

119. Tao WA, Cooks RG. Parallel reactions for enantiomeric quantification of peptides by mass spectrometry. Angew Chem Int Ed Engl 2001;40:757-760. [PubMed: 11241614]

120. Jimenez EC, Watkins M, Juszczak LJ, et al. Contryphans from Conus textile venom ducts. Toxicon 2001;39:803-808. [PubMed: 11137539]

121. Kuwada M, Teramoto T, Kumagaye KY, et al. Omega-agatoxin-TK containing D-serine at position 46, but not synthetic omega-[L-Ser46]agatoxin-TK, exerts blockade of P-type calcium channels in cerebellar Purkinje neurons. Mol Pharmacol 1994;46:587-593. [PubMed: 7969037] 


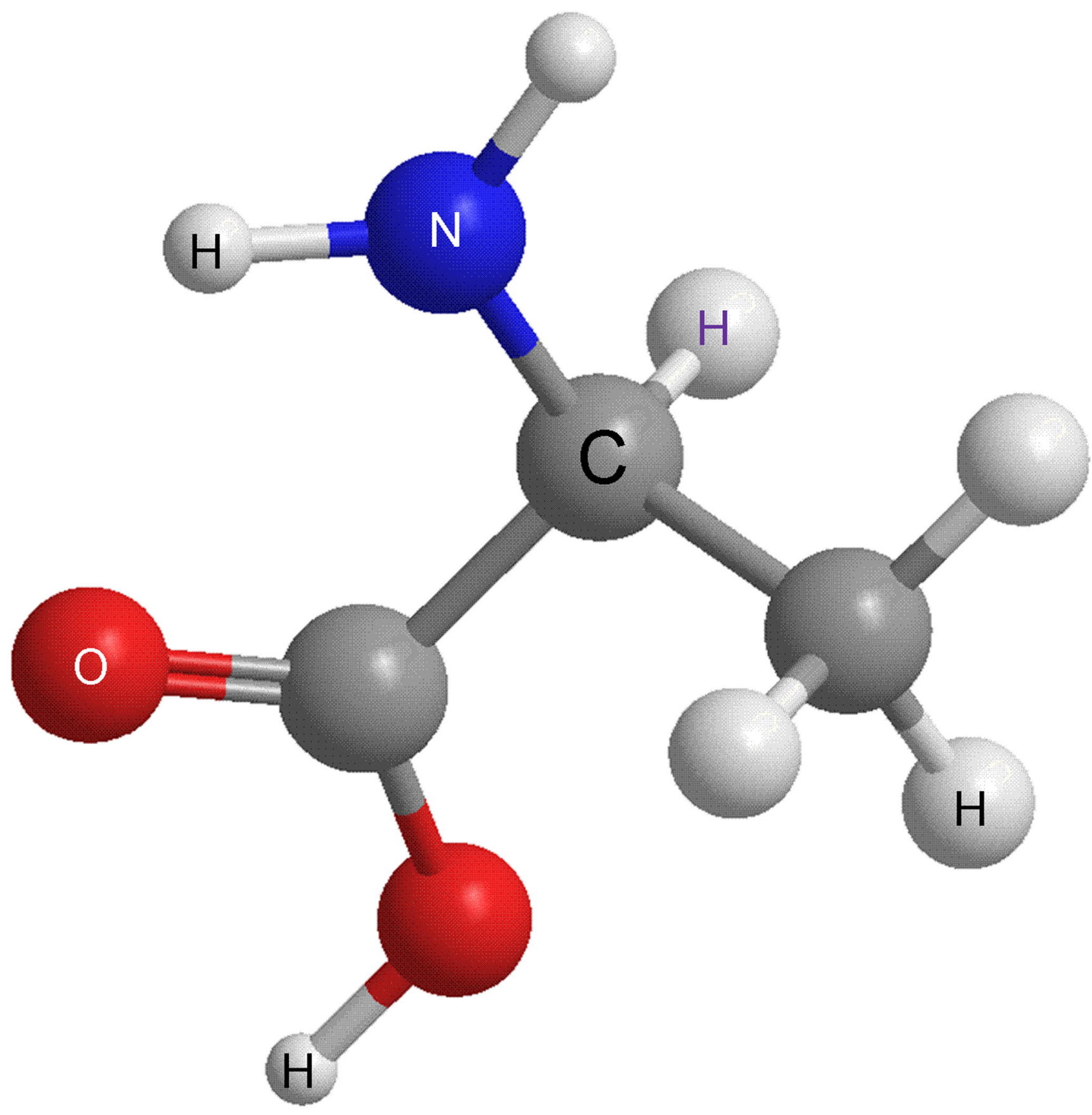

Fig. 1.

Ball-and-stick illustration of an L-amino acid (L-alanine) with - $\mathrm{COOH}$, -NH2 and -R groups arranged clockwise around the carbon chiral center when viewing with - $\mathrm{H}$ away from the center. Carbon atoms (grey), nitrogen (blue), hydrogen (white), and oxygen (red). The D-amino acid has the counterclockwise arrangement around the chiral center. 


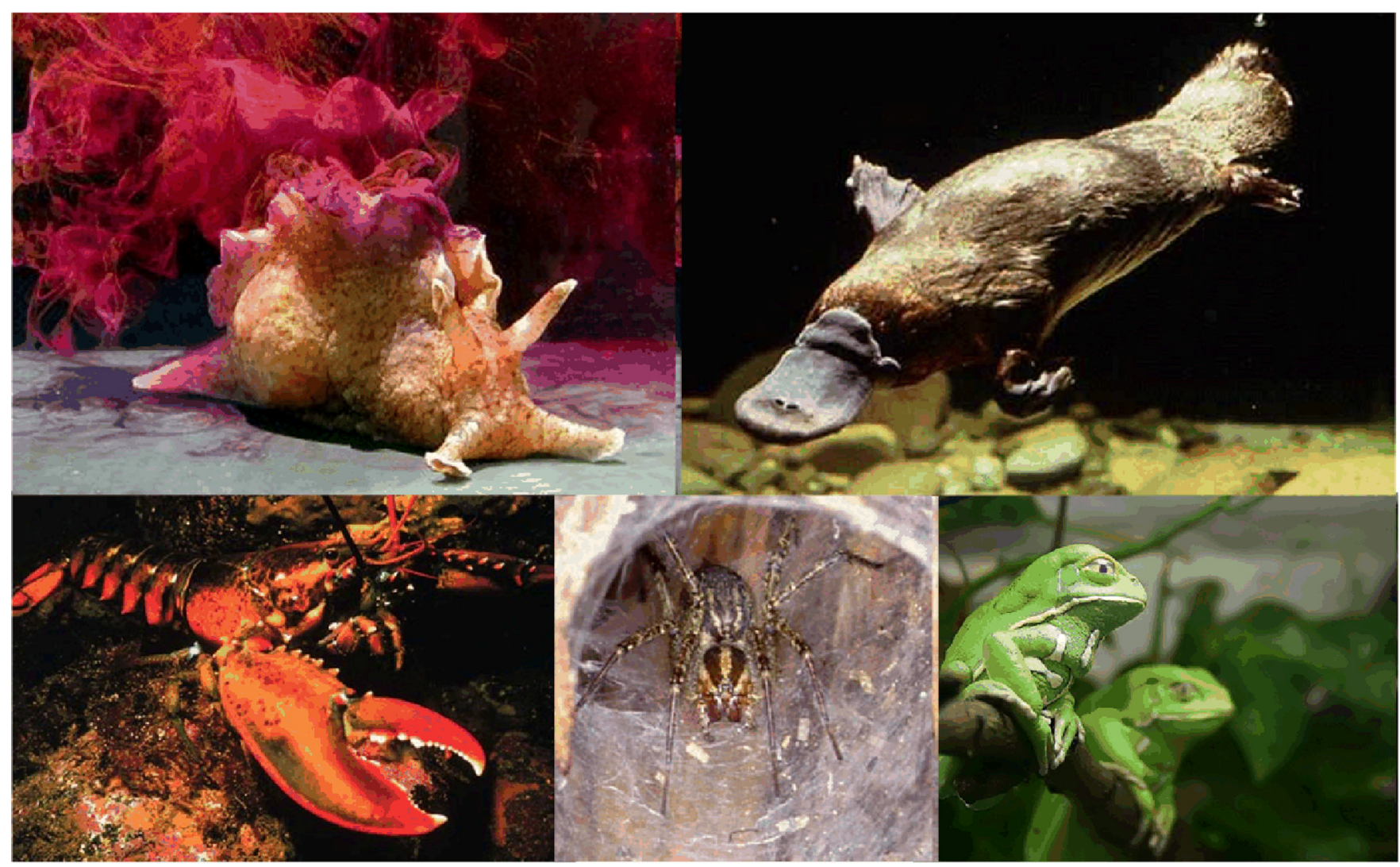

Fig. 2.

DAACPs have been found in a surprising range of species in Metazoa; for example (top row), sea slug Aplysia californica [114], platypus Ornithorhynchus anatinu [115], (bottom row) lobster Homarus americanus [116], funnel-web spider Agelenopsis aperta [117], and South American tree frog Phyllomedusa sauvagei [118]. Photos used with permission. 
ABSORBANCE $(220 \mathrm{~nm})$

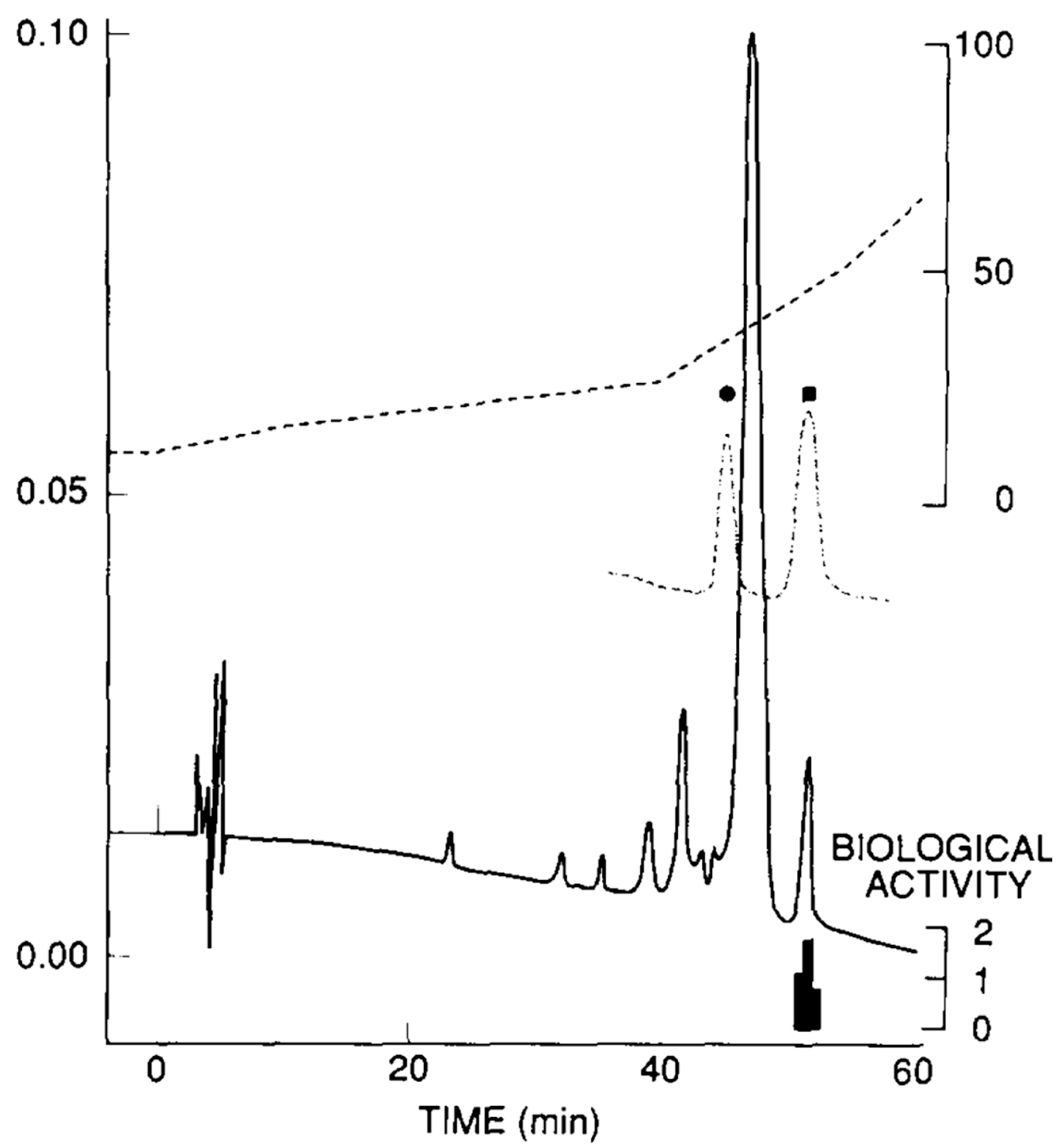

Fig. 3.

Elution profile of an active fraction isolated from skin secretions of Phyllomedusa sauvagei on a Supelcosil LC18DB column without chiral selectors. Synthetic deltorphin diastereomers, [L-Met2]deltorphin (solid circle) and deltorphin (solid square), were used as reference standards (dashed curves). The active fraction (indicated by the height of the lower black bars underneath) has the same elution time with deltorphin. Reproduced with permission from Elsevier [6]. 
A<smiles>O=C(O)C1OCCOCCO[C@H](C(=O)O)[C@@H](C(=O)O)OCCOCCO1</smiles>

(-)-(18-crown-6)-2,3,11,12-tetracarboxylic acid

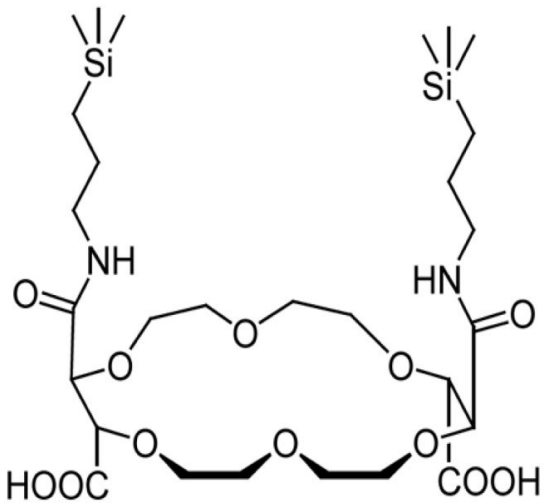

chiral CSP

B

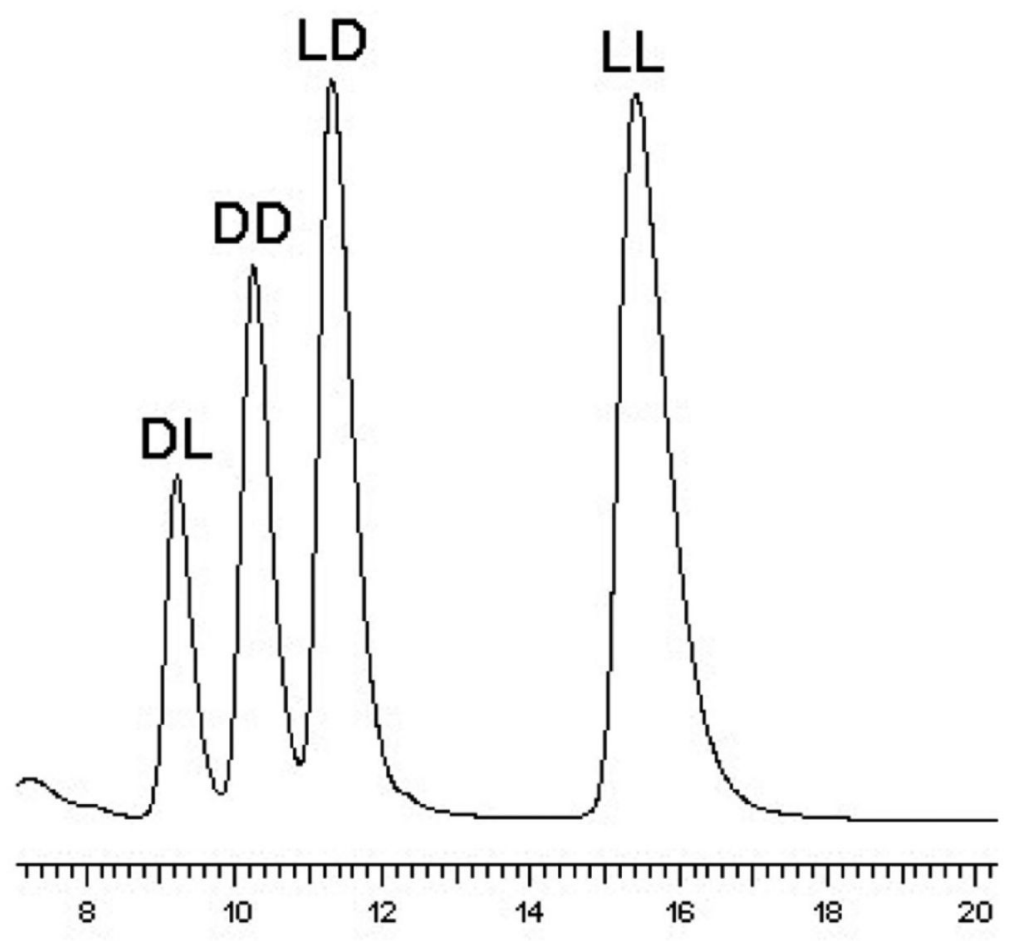

Fig. 4.

(A) Crown ether (-)-(18-Crown-6)-tetracarboxylic acid. (B) HPLC separation of Ala-Phe stereoisomers on a (-)-(18-Crown-6)-tetracarboxylic acid-based column. Interaction between protonated amine groups in peptides and oxygen atoms lining the inner surface of the crown ether molecule is the basis of chiral selectivity. $10 \mathrm{mM}$ sulfuric acid in $70 \%$ methanol-water was used as mobile phase to facilitate protonation of amine groups. Adapted with permission from Wiley-VCH Verlag GmbH \& Co. KGaA [62]. 

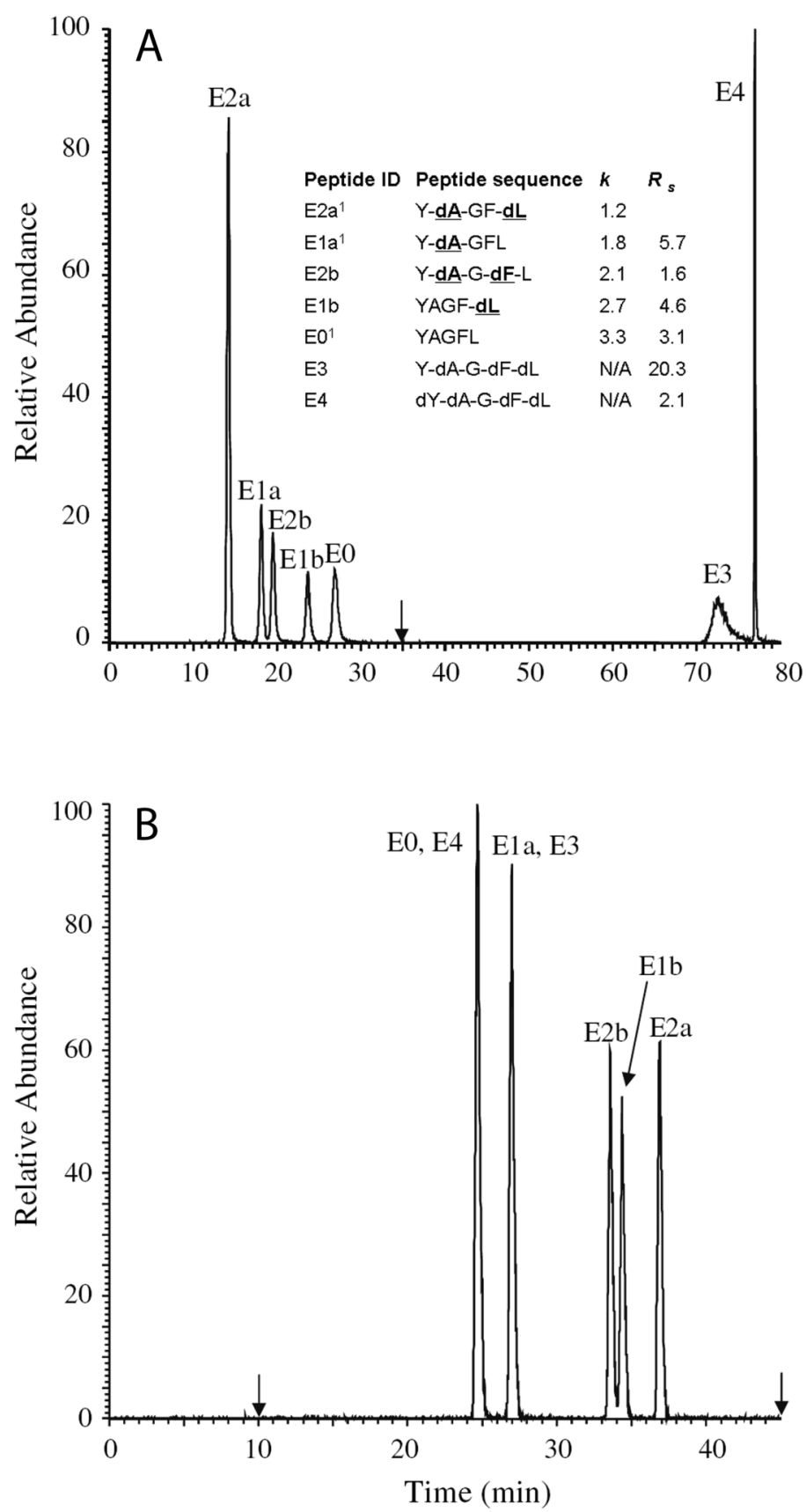

Fig. 5.

HPLC separations of enkephalin diastereomers on (A) teicoplanin stationary phase compared to (B) $\mathrm{C} 18$ stationary phases. The arrow in (A) indicates the beginning of a step gradient (from isocratic $78 \% \mathrm{ACN} / 22 \% 3 \mathrm{mM}$ ammonium acetate to $70 \% \mathrm{CAN} / 30 \% 0.1 \%(\mathrm{v} / \mathrm{v})$ formic acid in water at $36 \mathrm{~min}$ ) found necessary to decrease the elution time of E3 and E4. Arrows in (B) indicate the linear gradient in between $(80 \% 13 \mathrm{mM}$ ammonium acetate $/ 20 \% \mathrm{ACN}$ at $10 \mathrm{~min}$ to $30 \% \mathrm{ACN}$ at $45 \mathrm{~min}$ ). These two stationary phases are different in selectivity and thus peptides have different retention orders. Enantiomeric pair E0 and E4 and diastereomeric pair E1a and E3were not separated on the non-chiral column, whereas teicoplanin-based CSP was able to resolve every peptide. Adapted with permission from Springer [69]. 

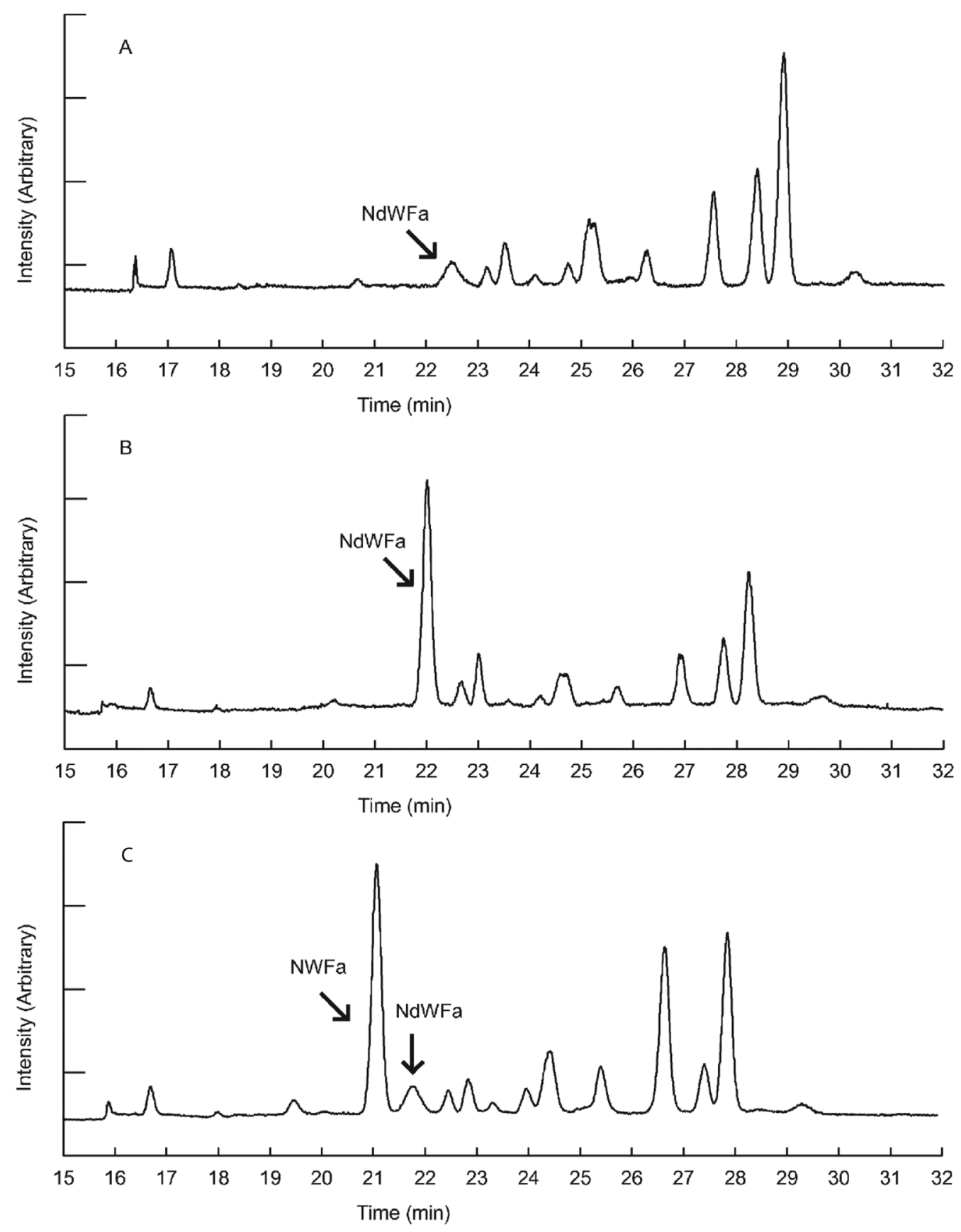

Fig. 6.

Characterization of NdWFa using CE in a single Aplysia ventral abdominal neuron. (A) Representative electropherogram obtained from a single ventral abdominal neuron. (B) CE electropherogram of a ventral abdominal neuron spiked with synthetic NdWFa standard. (C) Electropherogram of a ventral abdominal neuron spiked with synthetic NWFa standard, which migrates faster than the endogenous NdWFa peak. The measurement has been repeated three times on different peptidergic neurons. Reproduced with permission from the Royal Society of Chemistry [44]. 

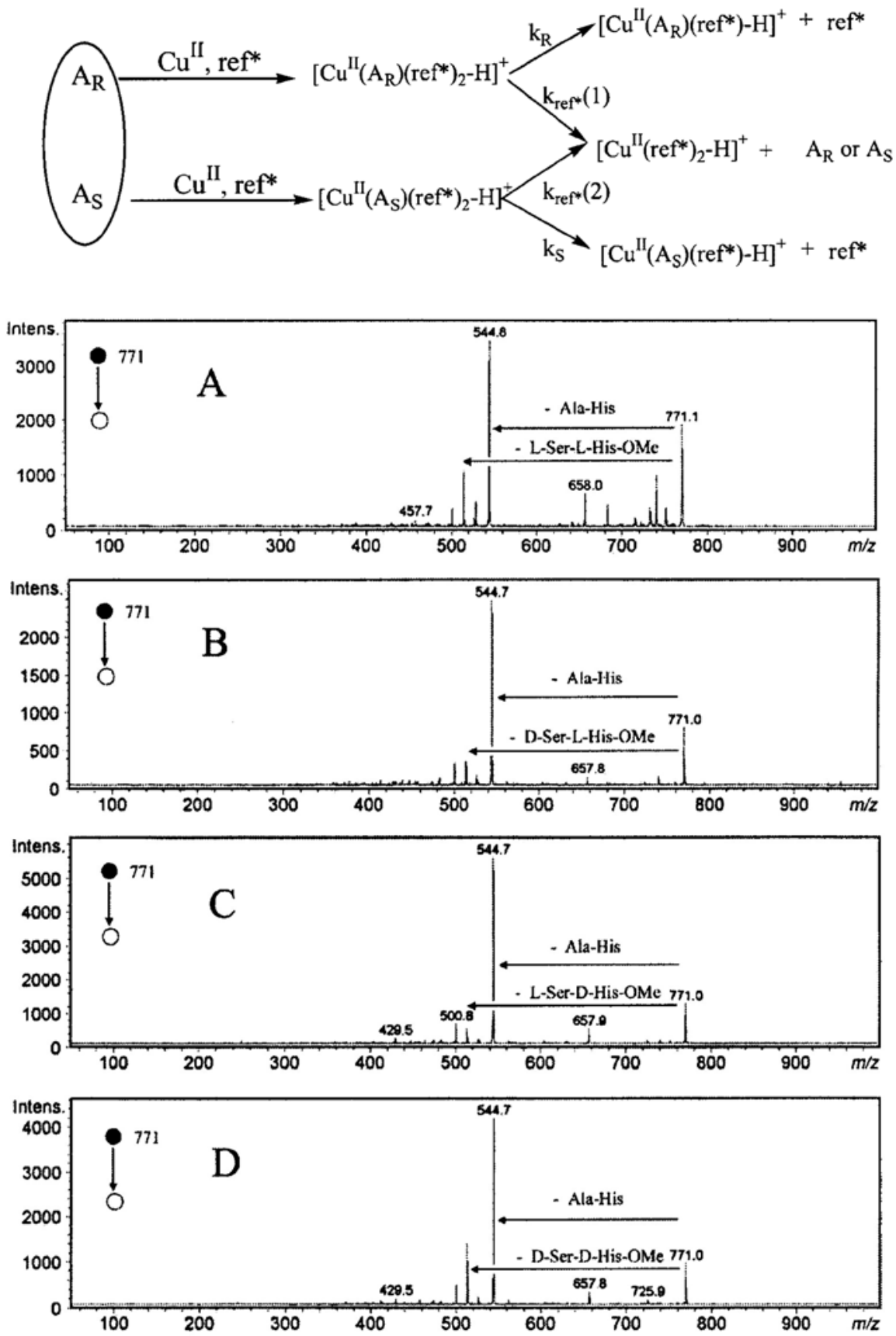

Fig. 7.

The top scheme illustrates the principle of kinetic method and the bottom multipart figure shows the CID fragmentation patterns of $\left[\mathrm{CuII}(\mathrm{A})\left(\mathrm{ref}^{*}\right) 2-\mathrm{H}\right]+(\mathrm{m} / \mathrm{z} 771)$, with the ref* molecule being Ala-His dipeptide, and various analytes: (A) A = L-Ser-L-His-OMe; (B) DSer-L-His-OMe; (C) L-Ser-D-His-OMe ; and (D) D-Ser-D-His-OMe. Patterns of competitive collision for each stereoisomeric complex depend on their respective stabilities, therefore, the abundance ratio $\mathrm{Re}=\left[\mathrm{CuII}(\mathrm{A})\left(\mathrm{ref}^{*}\right)-\mathrm{H}\right]+/\left[\mathrm{CuII}\left(\mathrm{ref}^{*}\right) 2-\mathrm{H}\right]+$ of different complexes can be used to measure the relative abundance of stereoisomers when a calibration curve is available. Top panel [119] and bottom panel [95] are adapted with permission from Wiley-Blackwell. 

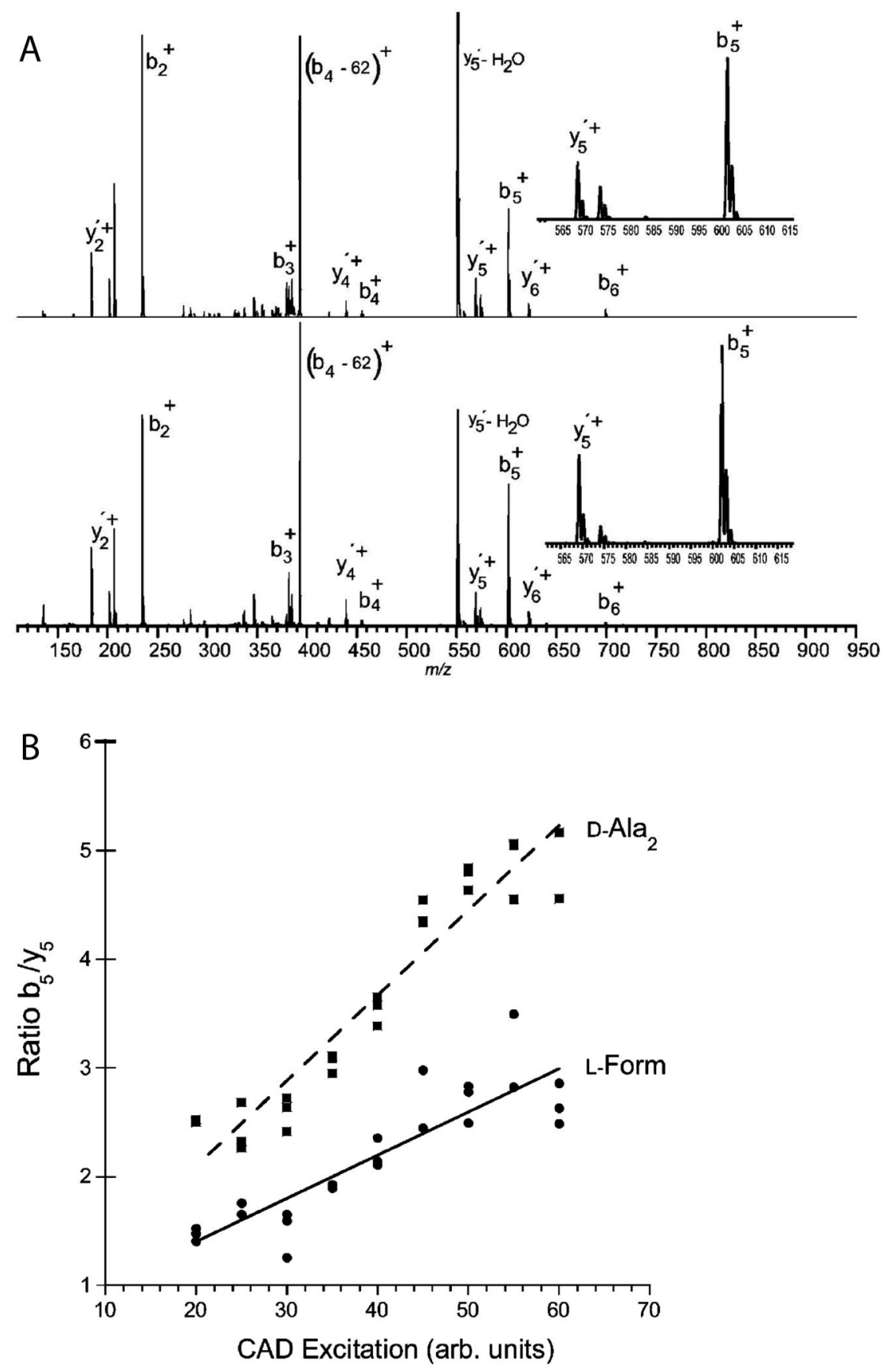

Fig. 8.

(A) Comparison of CAD fragmentation patterns generated from dermorphins, all-L form (top) and $\mathrm{D}-\mathrm{Ala}^{2}$ form (bottom). Relative abundance of $\mathrm{b}^{+}$and $\mathrm{y} 5^{+}$fragment ions, shown in upper right insets, is used for chiral composition determination. $\mathrm{R}_{\mathrm{L}}$ (ratio $\mathrm{b}_{5} / \mathrm{y}_{5}$ for $\mathrm{L}$-form) is about 2.3 and $\mathrm{R}_{\mathrm{D}}$ is about 4.8 at 50 arbitrary CAD excitation units. (B) The ratios of the chiralityreporting fragment ion pairs $\mathrm{b}_{5} / \mathrm{y}_{5}$ as a function of CAD excitation intensities in arbitrary units. The chiral recognition factor $R_{\text {chiral }}$ (ratio $R_{D} / R_{L}$ ) is relatively constant at different excitation levels. Adapted with permission from the American Chemical Society [101]. 

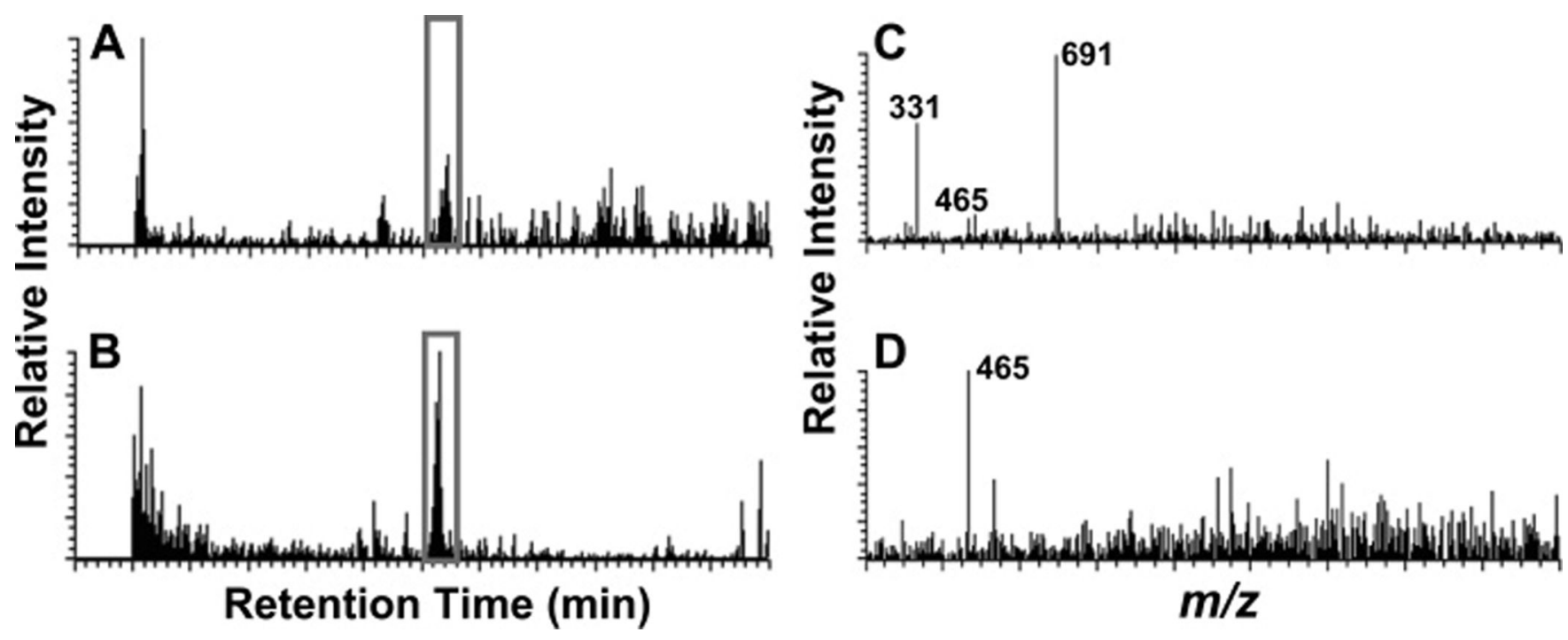

Fig. 9.

Characterization of DAACPs from a complex mixture of peptides using an enzymatic digestion method. Aplysia abdominal ganglia were used to make extract. (A) and (B) are LC base peak chromatograms showing $465-466 \mathrm{~m} / \mathrm{z}$ range, which matches the $\mathrm{NWFa} / \mathrm{NdWFa}$ peak, without enzyme treatment (A) or with 1.0 units of mAAP treatment (B). (C) and (D) are corresponding MS spectra showing NWFa/NdWFa peaks. Enzymatic treatment facilitated detection of otherwise barely detectable peptides. Reproduced with permission from the American Chemical Society [113]. 
Table 1

More than 30 DAACPs have been discovered in the last 38 years.

\begin{tabular}{|c|c|c|c|}
\hline Source & Peptide [Reference] & Sequence 1 & Species \\
\hline \multirow{3}{*}{$\begin{array}{l}\text { land mollusc Achatina } \\
\text { neuropeptides }\end{array}$} & Achatin I [11] & G $\underline{\mathrm{dFAD}}$ & Achatina fulica \\
\hline & Fulicin [43] & FdNEFVa & Achatina fulica \\
\hline & Fulyal [12] & Y $\underline{\mathrm{dAEFLa}}$ & Achatina fulica \\
\hline \multirow{14}{*}{$\begin{array}{l}\underset{\text { marine mollusc Conus }}{\text { toxin }} \\
\text { mats }\end{array}$} & Contryphan [14] & GCOdWEPWCa & Conus radiatus \\
\hline & Des-[Gly 1]contryphan-R [14] & COdWEPWCa & Conus radiatus \\
\hline & Contryphan-P [16] & GCP吕DPWCa & Conus purpurascens \\
\hline & Contryphan-Sm [16] & GCO $\underline{\mathrm{dWQPWCa}}$ & Conus stercusmuscarum \\
\hline & Bromocontryphan-R [15] & GCOdWEPW(6-bromo-W)Ca & Conus radiatus \\
\hline & Contryphan-R [16] & GCOdWEPWCa(disulfide bond) & Conus radiatus \\
\hline & Leu-Contryphan-P [17] & GCV $\underline{\mathrm{dLLPWC}}$ & Conus purpurascens \\
\hline & Leu-contryphan-Tx [120] & CV $\underline{\mathrm{dL} Y P W C a}$ & Conus textile \\
\hline & Contryphan-Tx [120] & GCOdWQPYCa & Conus textile \\
\hline & R11a (I-superfamily) [19] & $\mathrm{dF}$ at 44 th in 46 a.a. & Conus radiatus \\
\hline & $\mathrm{R} 11 \mathrm{~b}, \mathrm{c}[18]$ & $\mathrm{dF}$ at 44 th in 46 a.a., $\mathrm{dL}$ at $42 \mathrm{nd}$ in 44 a.a. & Conus radiatus \\
\hline & Conomap-Vt [21] & AdFVKGSAQRVAHGY & Conus vitulinus \\
\hline & $\begin{array}{c}\text { Conomarphin (M super family) } \\
\text { [22] }\end{array}$ & DWEYHAHPKONS $\underline{\mathrm{dFWT}}$ & Conus marmoreus \\
\hline & Conophan [23] & AOANSdVWS & Conus gladiator \\
\hline \multirow{3}{*}{$\begin{array}{l}\text { other marine molluscan } \\
\text { peptides }\end{array}$} & NdWFa [13] & $\mathrm{NdWFa}$ & Aplysia kurodai \\
\hline & Mytilus-FFRF amide [25] & AdLAGDHFFRFa & Mytilus edulis \\
\hline & Ocp-1/4 [24] & 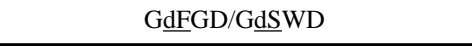 & Octopus minor \\
\hline \multirow{2}{*}{$\begin{array}{l}\text { crustacean hyperglycemic } \\
\text { hormone }\end{array}$} & CHHA, cHHB [26] & pGlu-V $\underline{\text { dFDQACK }}$ & Homarus americanus \\
\hline & Prc CHH-II [27] & $\mathrm{dF}$ at $3 \mathrm{rd}$ in 72 a.a. & Procambarus clarkii(crayfish) \\
\hline spider venom peptide & IVB ( $\omega$-agatoxin-TK) $[28,121]$ & dS at 46 th 46 a.a. & Agelenopsis aperta \\
\hline \multirow{6}{*}{ frog skin toxin } & Dermorphin [5] & Y $\underline{\text { dAFGYPSa }}$ & Phyllomedusa sauvagei \\
\hline & Deltorphin(met) [6] & Y $\underline{\mathrm{dMFHLMDa}}$ & Phyllomedusa sauvagei \\
\hline & Deltorphin(leu) [7] & Y $\underline{\text { dLFADVASTIGDFFHSIa }}$ & Phyllomedusa burmeisteri \\
\hline & $\begin{array}{c}\text { Deltorphin A (Dermenkephalin) } \\
\text { [8] }\end{array}$ & Y $\underline{\mathrm{dMFHLMDa}}$ & Phyllomedusa sauvagei \\
\hline & Deltorphins I (B) II (C) (ala) [9] & $\mathrm{Y} \underline{\mathrm{dAFD}}(\mathrm{E}) \mathrm{VVGa}$ & Phyllomedusa bicolor \\
\hline & Bombinin (H3-H5) [10] & D-alle at $2 n d$ in 21 a.a. & Bombina variegata \\
\hline \multirow{2}{*}{ platypus peptides } & Platypus peptide (OvCNPb) [29] & $\begin{array}{l}\text { LdLHDHPNPRKYKPANKKGLSKGCFG } \\
\text { LKLDRIGSTSGLGC }\end{array}$ & Ornithorhynchus anatinus \\
\hline & DLP-2 [30] & $\mathrm{dM}$ at $2 \mathrm{nd}$ in 42 a.a. & Ornithorhynchus anatinus \\
\hline
\end{tabular}

lEach amino acid is represented by its one letter abbreviation, the letter following a "d" indicates that amino acid is in D-form, and "a" means amidation of the C-terminal residue. 